\title{
الاستقرار الأسري وعلاقته بأساليب اتخاذ القرارات بالأسرة السعودية
}

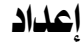 \\ د. نوره مسفر عطية الزهرانهــ \\ د.زينب محمد عبد الصمد عبد الجليل \\ محاضر بقسم الاقتصاد المنزلي \\ أستاذ مشارك بقسم الإسكان وأداره المنزل \\ بكلية العلوم والآداب بالمخواه جامعه الباحة \\ جامعه الملك عبد العزيز بجده
}

مجلة بحوث التربية النوعية - جامعة المنصورة

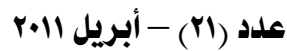




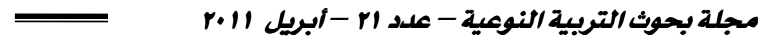

الاستقرار الأسري وعلاقته بأساليب اتخاذ القرارات بالأسرة السعودية

إعداد

د. نوره مسفر عطيةالزهراني

* ـ زينب محمد عبد الصمد عبد الجليل

טالl|

أهداف البحث : يهدف البحث إلى الكثف عن العلاقة بين الاستقرار الأسـري ودرجـة مشاركة

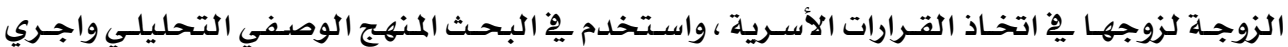

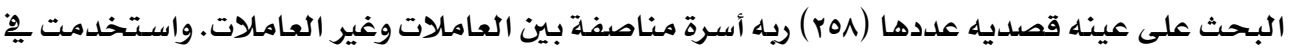
الدراسة ثلاثة استبيانات لقياس الاستقرار الأسـري ودرجة مشاركة الزوجة لزوجها يِّ اتخـاذ القـرارات

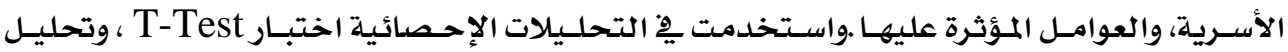
التبيـان الأحسادي ، واختبـار شـيفيه ومعامـل ارتبـاط بيرسـون بالإضـافة إلى التكـرارات والنسسب المئويـة والمتوسطات الحسـابية ـ وأسفرت النتائج عن عدم وجـود فروق ذات دلالـة إحصائية يِّ درجـة مشاركة

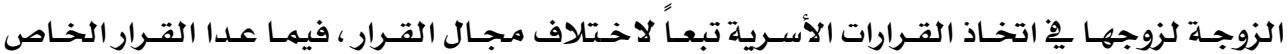

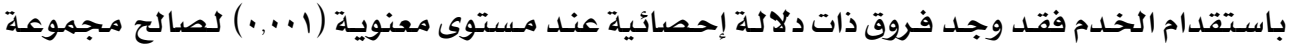

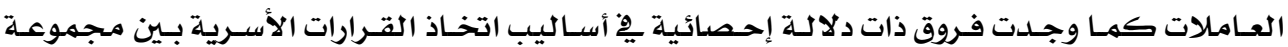
العاملات وغير العـاملات عند مستوى معنويـة (1.... ) . كمها أوضـحت النتائج وجـود علاقـة ارتباطيـه بين الاستقرار الأسري ودرجة مشاركة الزوجـة لزوجها يِّ اتخـاذ القرارات الأسـرية ( ا...) وعدم وجـود فروق ذات دلالـة إحصائية ِِّ أبعـاد الاستقرار الأسـري بـين مجموعـة العـاملات وغير العـاملات. كمها بينت النتائج فروق ذات دلالة إحصائية بين المتغيرات الاجتماعية والاقتصادية للأسرة ودرجة مشاركة

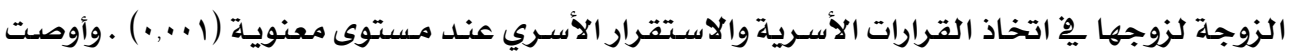
الدراسة بأهميـة توعيـة الزوجين بالمشاركة يِّا القـرارات الأسـرية مـن خـلال وسـائل الإعلام والمؤسسـات المعنية بشئون الأسرة، والاهتمام بوضع الخطط والبر امـج التي ترفع من مستوى الأسرة 


\section{Research summary}

The study is intended to investigate into the relationship between household stability and degree of wife's participation in household decisions, the researcher uses the descriptive analytical method, and the research was applied to a purposive sample size (258) of family housewives distributed on equal basis between working and non working group. In the study three Questionnaires were used to measure household stability and the degree of wife's participation to her husband in household decision making, and the factors affected it. The statistical analysis tests used in the analysis includes, T-Test, One Way Analysis of variances, Scheeffe Test, and person's Correlation Coefficient, in addition to that it uses frequencies, percentages, and averages.

The results have discovered that there is No significant statistical variations in degree of wife's participation in household decision making according to varied decision areas, except in area of housemaid hiring which shows statistical variance among working and non working group at ( 0.001) level, in favor of working groups, also there are significant statistical variations in decision making methods between couples in both working and non- working groups at significant level ( 0.001). also the results have shown that there is positive correlation between household stability and degree of wife's participation with husband in household decisions at significant level ( 0.01), and there is no statistical significant variation in household stability dimensions in both groups. The results also showed that there are significant statistical variations between socioeconomic variables and the degree of wife's participation to her husband in household decision making and household stability at significant level (0.001)

In the light of the findings reached, the study concludes, it is very important to raise the awareness of family on the importance of couples participation in household decisions, because it will enhance the consistency and stability of family, through different media channels and family concerned institutions, and paying attention to design special program and plans that help household members to increase their income and their educational level through the efforts of the concerned institutions. 
تعـد الأسـرة الوحـدة البنائيـة الأسـاسية لمختلف المجتمعـات الإنسانية فهي التي تقوم بالدور

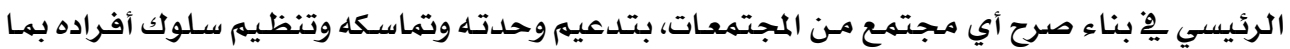

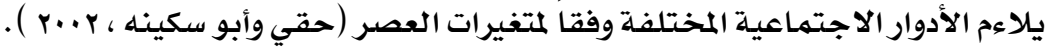
وتكـثف العلاقـات الأســريـة عـن الـتغيرات الـتي لحقـت ببنـاء الأسـرة ووظائفهـا وعلاقاتهـا

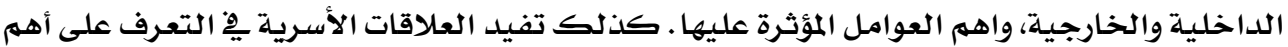

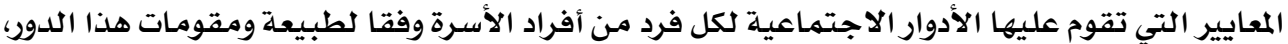

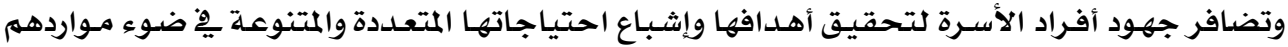

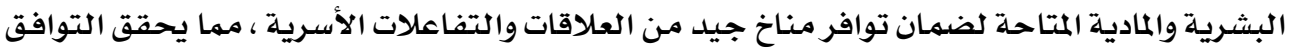
الزواجى والأسرى. (توفيق، 1997 ) .

والحياة سلسلة مـن القـرارات يتخـذها الفـرد ِِِ بيئتسه وفى المواقف التي يهـر بها، والقـرارات

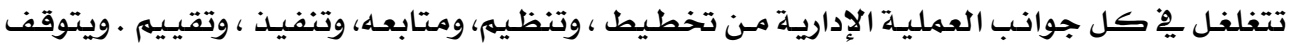

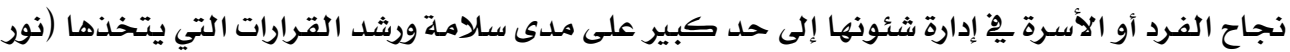

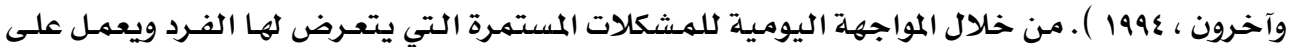
حلها (فتحي، ... ( ب ).

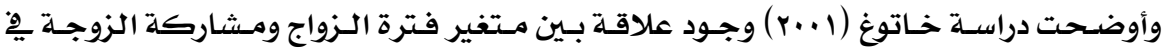

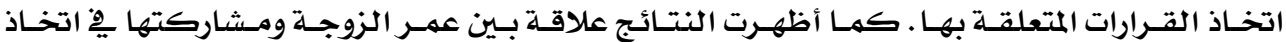
القرارات الخاصة بها

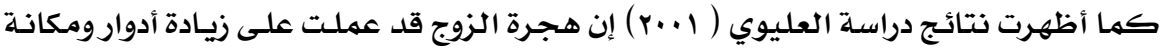

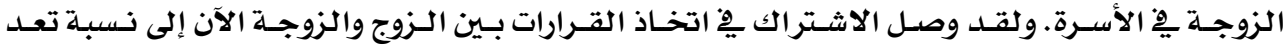

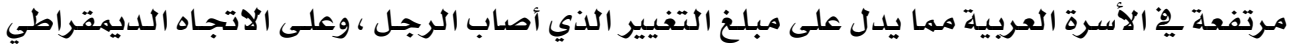

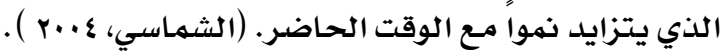
وتعـد القـرارات بالمشـاركة ثهـرة جهـلـ ومسشاركة مـن جانـب متتخـذي القـرارات وهـذا يعكس

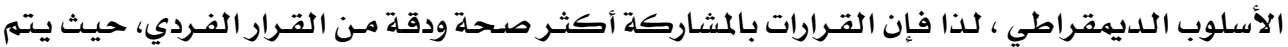


تجميع المعلومـات مـن خـلال الجماعـة، ورؤيـة موضـوعية مـن أكثر مـن زاويـة وبعـلد، كهـا أن المشاركة

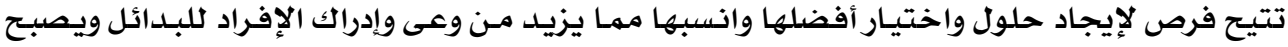

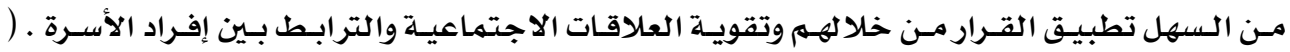

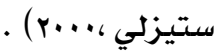

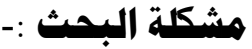

تتؤدي المشاركة يِّ اتخـاذ القـرارات إلى تقويـة الـروابط والعلاقات الأسـرية بـين أفراد الأسـرة،

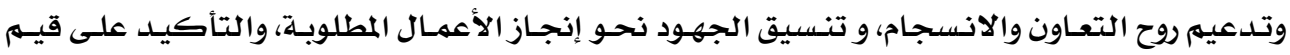

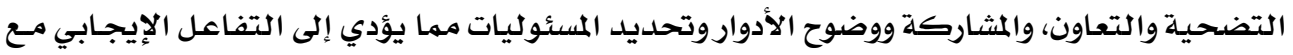
الحياة، وتمتع أفراد الأسرة بالصحة التشاروة النفسية .

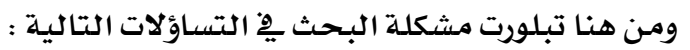
أ ) مـا مـدى مـشاركة الزوجـة لزوجها يِّ اتخـاذ القـرارات الأسـرية بالأسـرة السعودية ومـا العوامـل التي تؤثر على درجـة مشاركتها مـارها

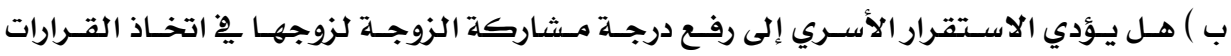
الأسريلة ؟

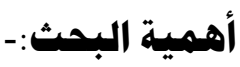

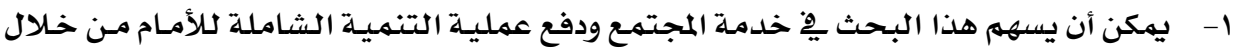

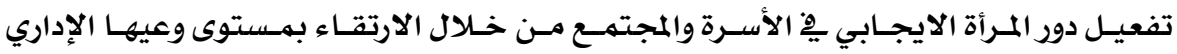

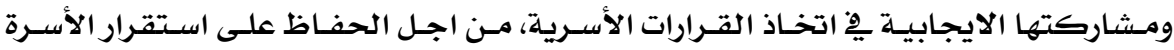

وتوازنها .

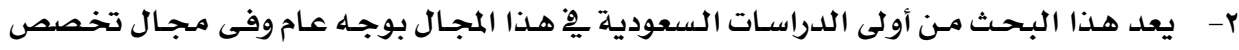
السكن وإدارة المنزل بوجه خاص، والذي يمكن الاستفادة من نتائجه بِّه تدعيم استقرار الأسرة السعودية.

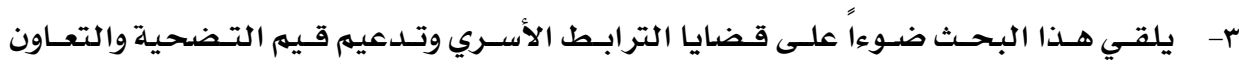

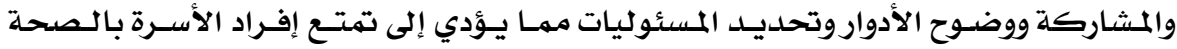

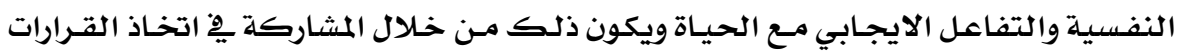

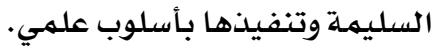

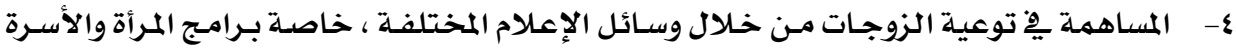

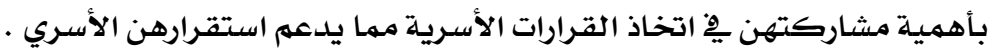
أهد|ف البحث :- أهميثة مشارث يهدف البحث بصورة رئيسيه إلى: الكشف عن العلاقة بين الاستقرار الأسري ودرجة مشاركة

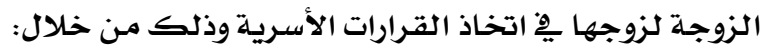




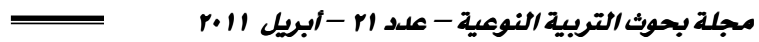

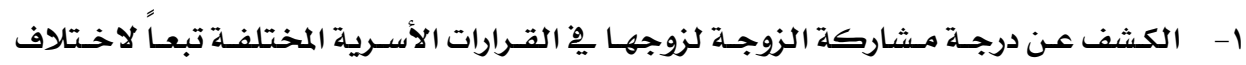

$$
\text { مجال القراربين العاملات وغير العامـلات . }
$$

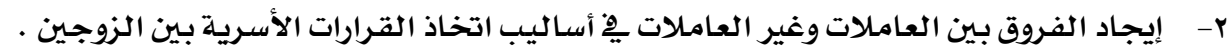

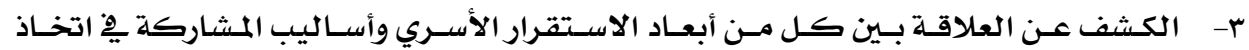

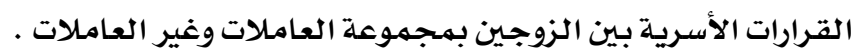

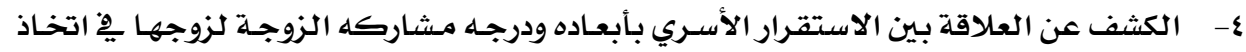

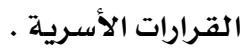

هـ التعرف على العلاقة بين أبعاد الاستقرار الأسـري والمتغيرات الاجتماعية والاقتصسادية للأسـرة ( دخل الأسـرة ، المستوى التعليهـي للـزوجـين ، حجهم الأسـرة ، مهنـة الـزوج ، مـدة الـزواج ، عمـر

$$
\text { الزوجهة" ) فِّ مجمهوعة العامـلات وغير العاملات. }
$$

\section{- : :}

• الاستقرار : Stability

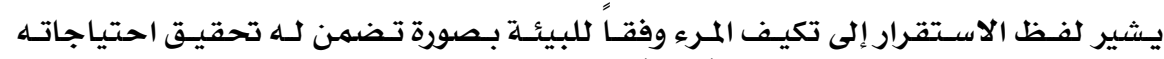
ومطالبـه بشكل مقبول، ويشكل الاستقرار توازنا تابتاً بـين الكـائن ومـا يحـيط بـه ، وإشـبـاعا لحاجتـه بهـا

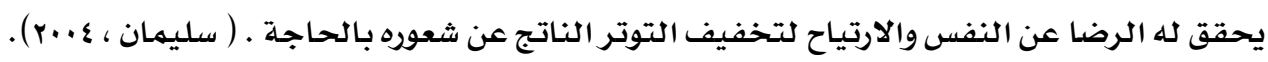

\section{ويعرف الاستقرار الأسري إجرائيا :}

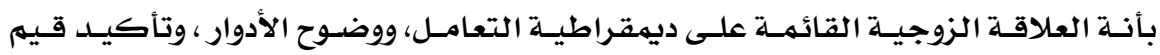

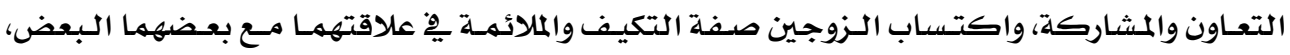

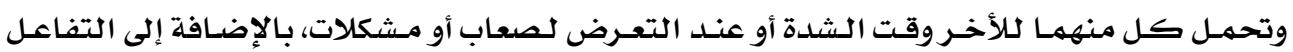
والتكيف مـع المؤثرات الخارجية بها يههد لحياة أسرية مستقرة ـ الباحثة

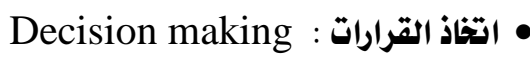

يعرف القرار بأنة الثبات على اختيار محدد أو إجراء معـين (Raymond , 1990). واتخـاذ

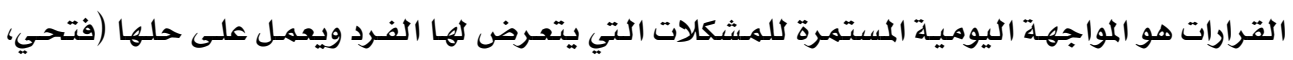

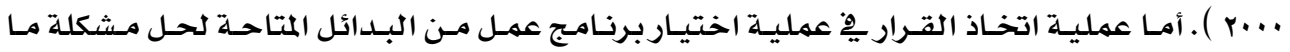

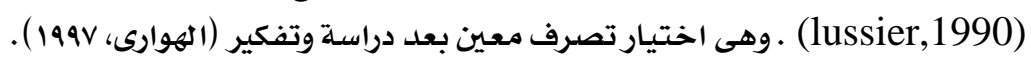
participation : المتاريار

تعنى الالتزام العقلي والعاطفي وهى ليست قاصـرة على النشـاط الجسسمي فقط، وهى تزيــ

من تقبل المسئولية والتحمس لتتفيذها من خلال الجماعة وتزيـد مـن الترابط بـين الأفراد وتتيح لهمه

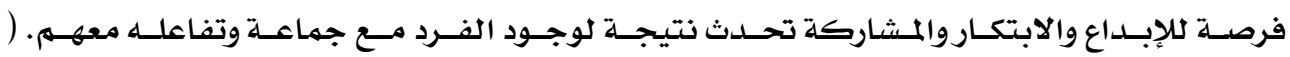


بأنها الاختيارات المقترحة من قبل الزوج والزوجة نتيجة خبر اتهما السابقة ويستقر رأيهما

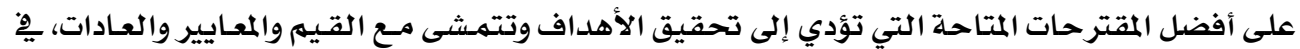

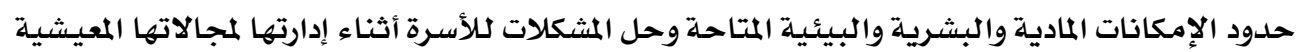

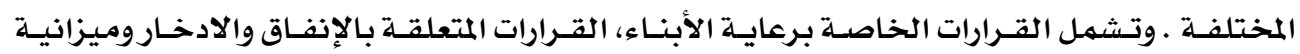

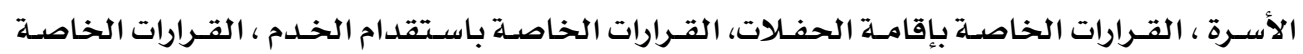

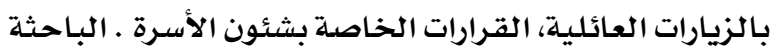

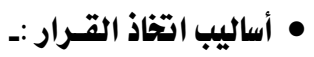

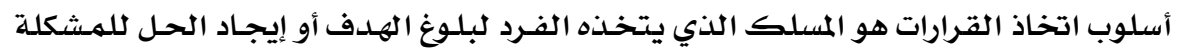

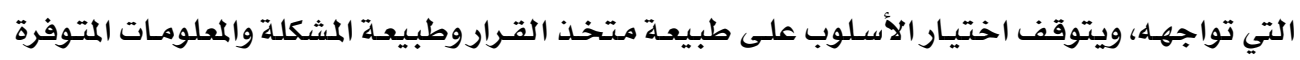

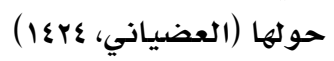

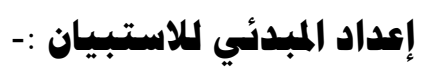

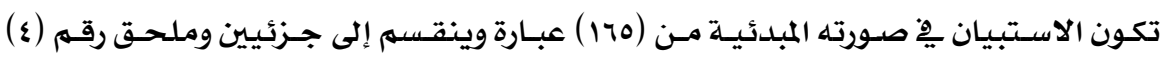

$$
\text { يوضح ذلك :- }
$$

الجزs الأوله يتكون من جزئيين هما :-

التفاعلات الشخصية بين إفراد الأسرة ، ويتكون من ( rV ) عبارة موزعة على أربعة أبعاد وهي

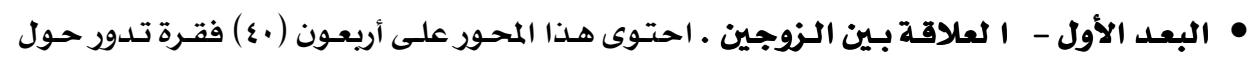

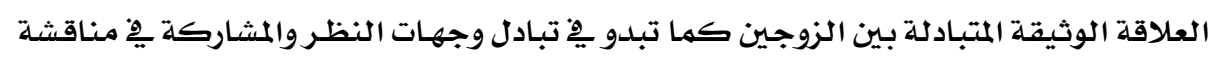

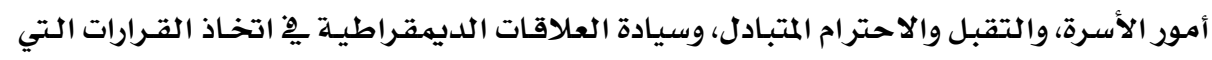

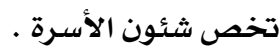

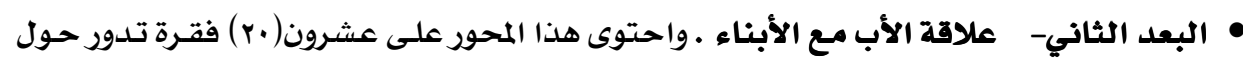

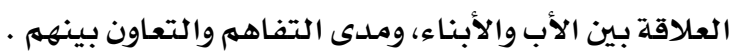

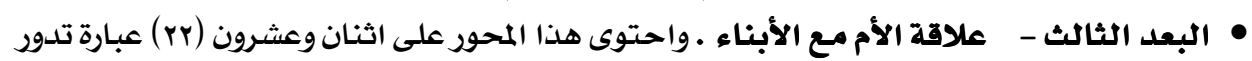

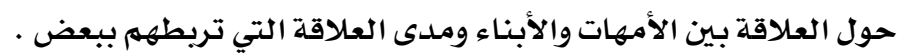

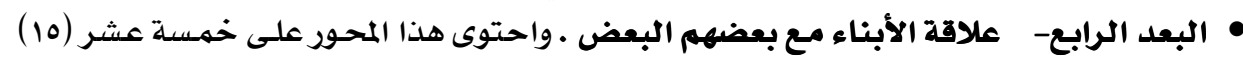

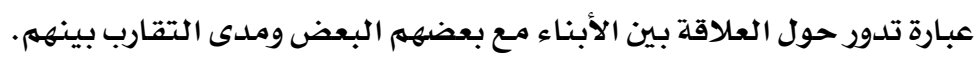

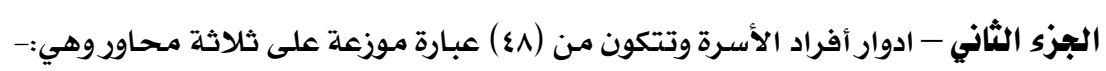

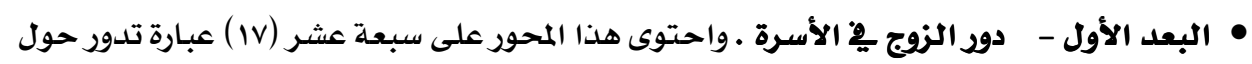

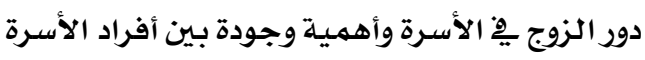

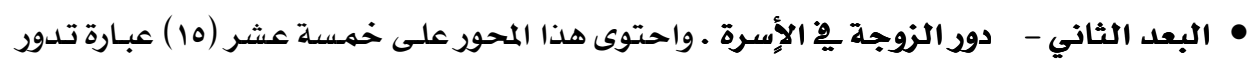

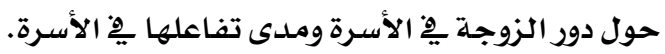




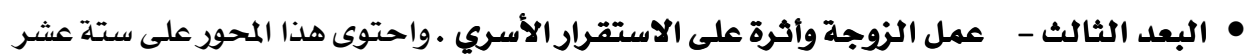

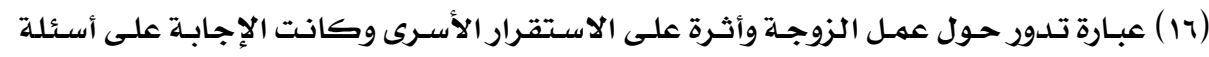

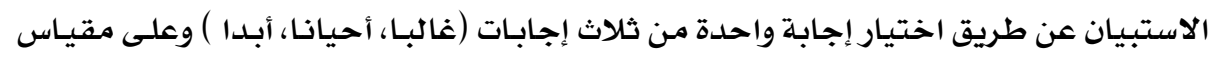

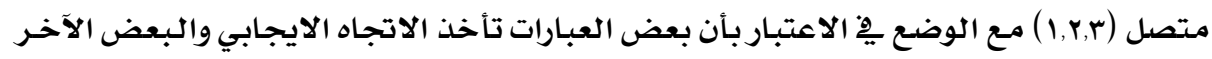

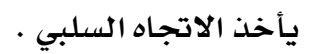

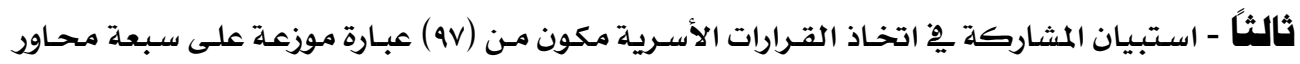

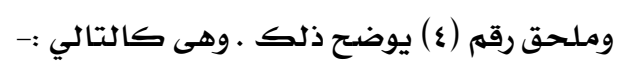

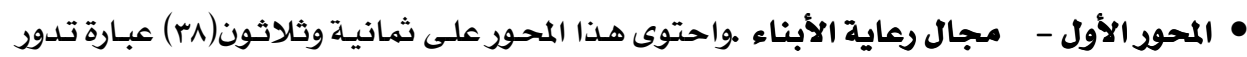

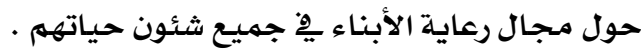

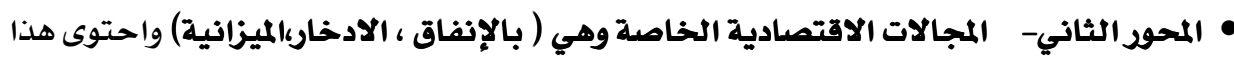

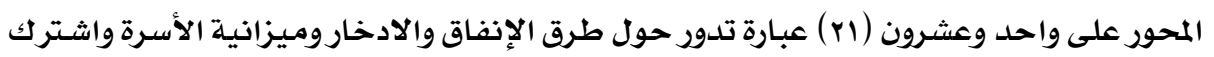

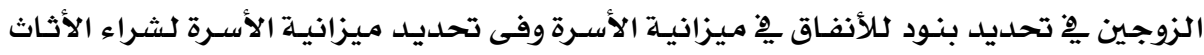

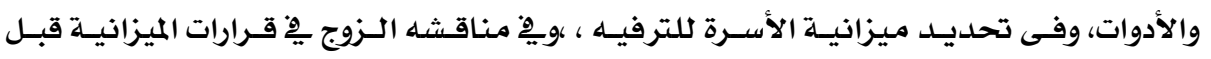

$$
\text { وضعها . }
$$

• المحور الثالث - إقامـة الحفلات ـواحتوى هذا المحور على ستة (7) عبـارات تلدور حول كيفيـة

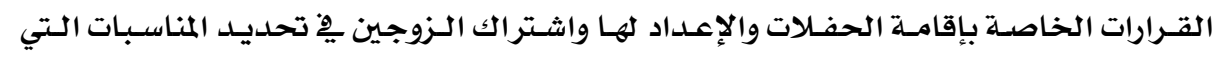

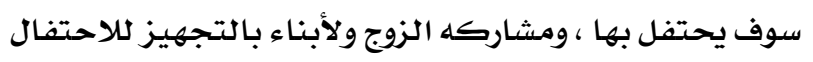

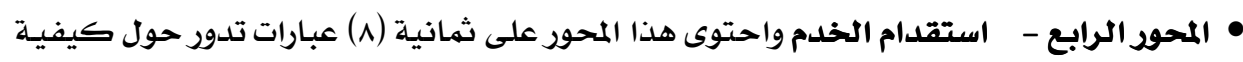

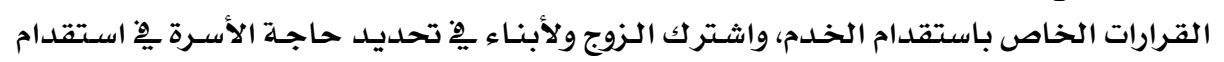

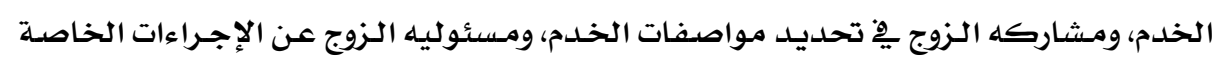

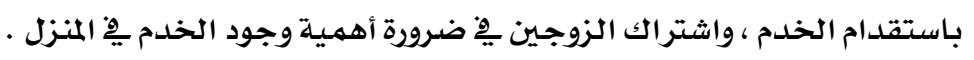

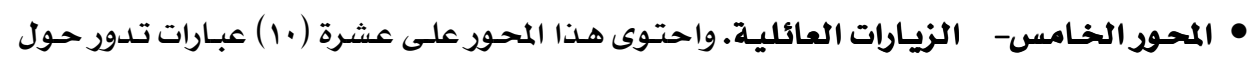

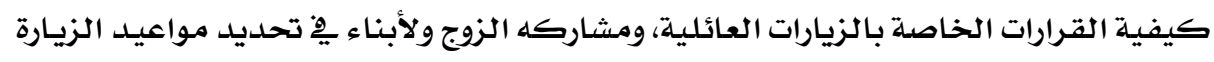

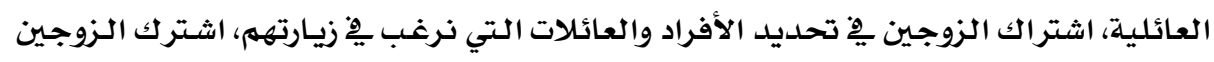
ولأبناء ِِّ تحديد زيارة الجيران.

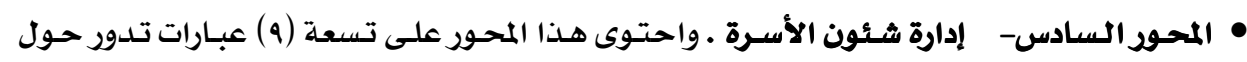

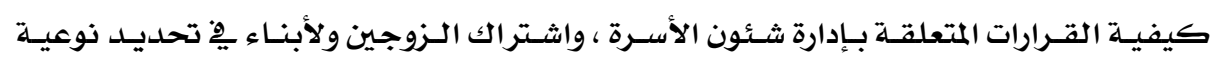

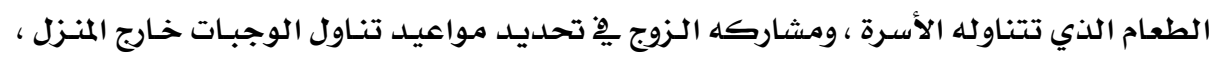

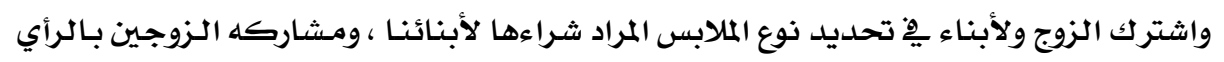

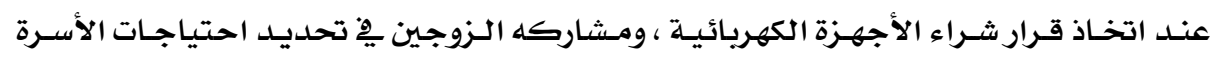
لبعض الأثاث. 
تم حساب صدق الاختبار عن طريق اختبار ألفا كرونباخ وكانت النتائج كالأتي :

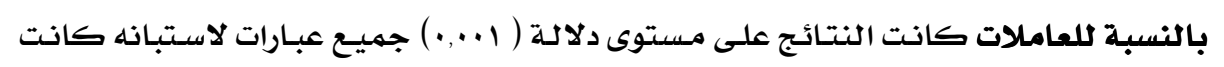

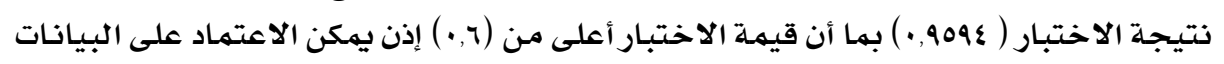

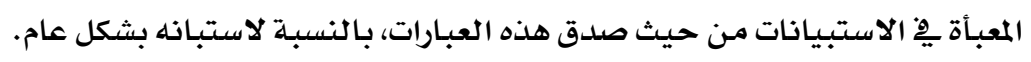

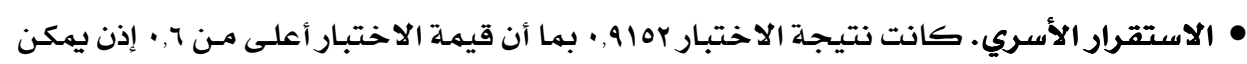

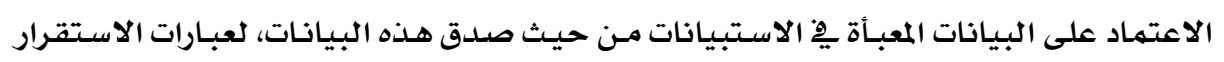
الأسري.

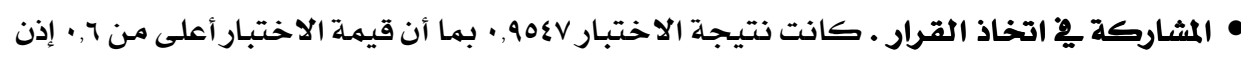

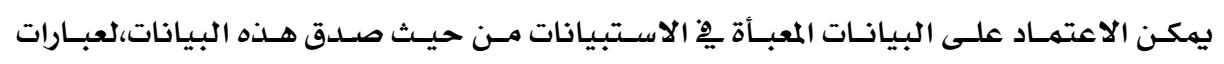
المشاركة يِّ اتخاذ القرار.

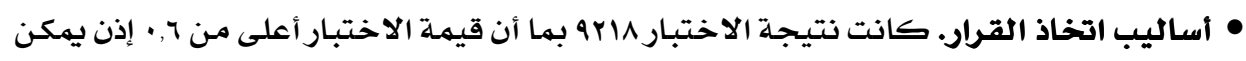

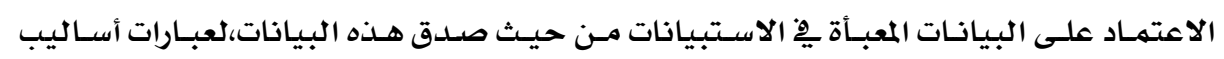
اتخاذ القرار

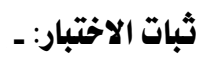

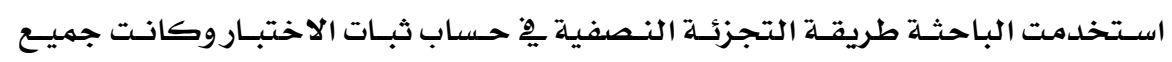

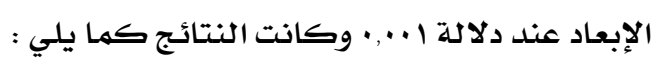

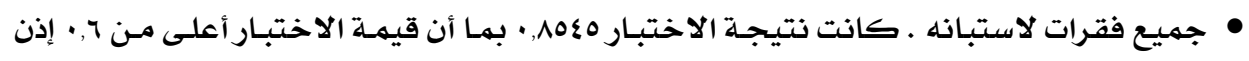

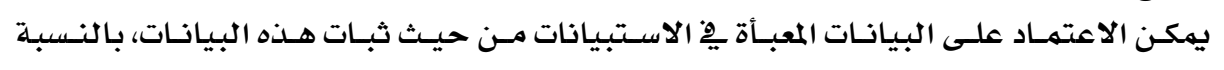

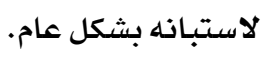

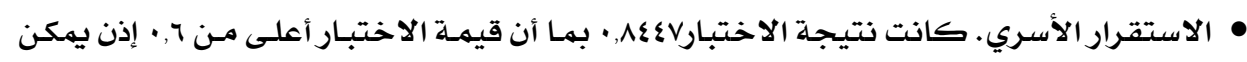

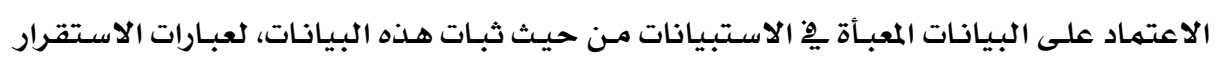
الأسري.

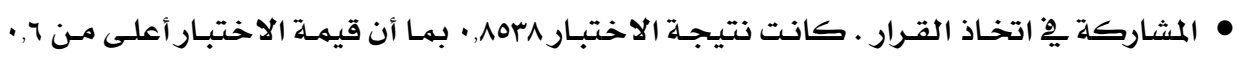

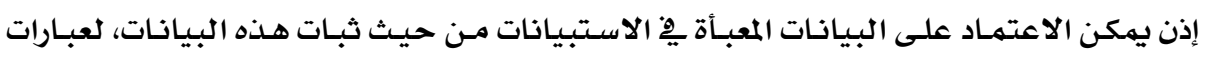
المشاركة يِّ اتخاذ القرار.

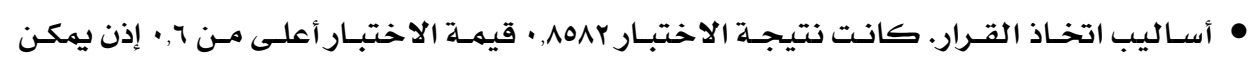

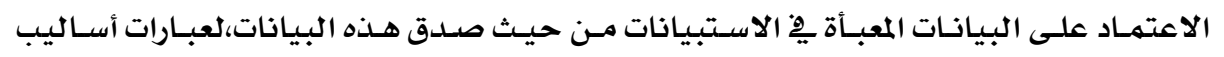
اتخاذ القرار 
ثبات أداة الدراسة.

بلغت قيمـة ألفا كرونبـاخ لثبـات أداة الدراسـة سـواء بالنسبة لثبـات أداة الدراسـة للعـاملات أو الدات

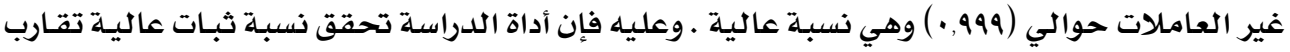

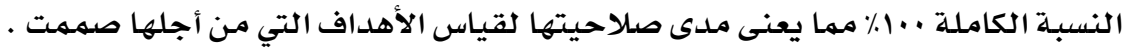

وصف العينة

اــمدة الزواج

جدول ( 1 ) توزيع أفراد عينة البحث وفقاً لمدة الزواج

\begin{tabular}{|c|c|c|c|c|}
\hline \multicolumn{2}{|c|}{ مجهموعة غير العامـلات } & \multicolumn{2}{|c|}{ مجمهوعة العامـلات } & \multirow{2}{*}{ مده الزواج } \\
\hline النسبــة المئويـة & العدد & النسبـة المئويـة & العدد ال العد & \\
\hline $0 \cdot, \cdot$ & $7 \varepsilon$ & rr & rq & من ه إلى هسنوات \\
\hline Yr, & $r$. & 17 & $\begin{aligned} Y_{1} \\
\end{aligned}$ & من+1 الىع اسنـة \\
\hline $11, \mathrm{~V}$ & 10 & 9 & ir & منئالى 19 اسنـة \\
\hline$\vee, \wedge$ & 1. & 17 & Yl & من ·rالى عاسنـة \\
\hline $\mathrm{V}, \cdot$ & 9 & m & $\varepsilon V$ & 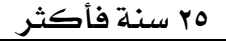 \\
\hline$\% 99,9$ & IYA & $\% 1+$ & Ir. & المجموع \\
\hline
\end{tabular}

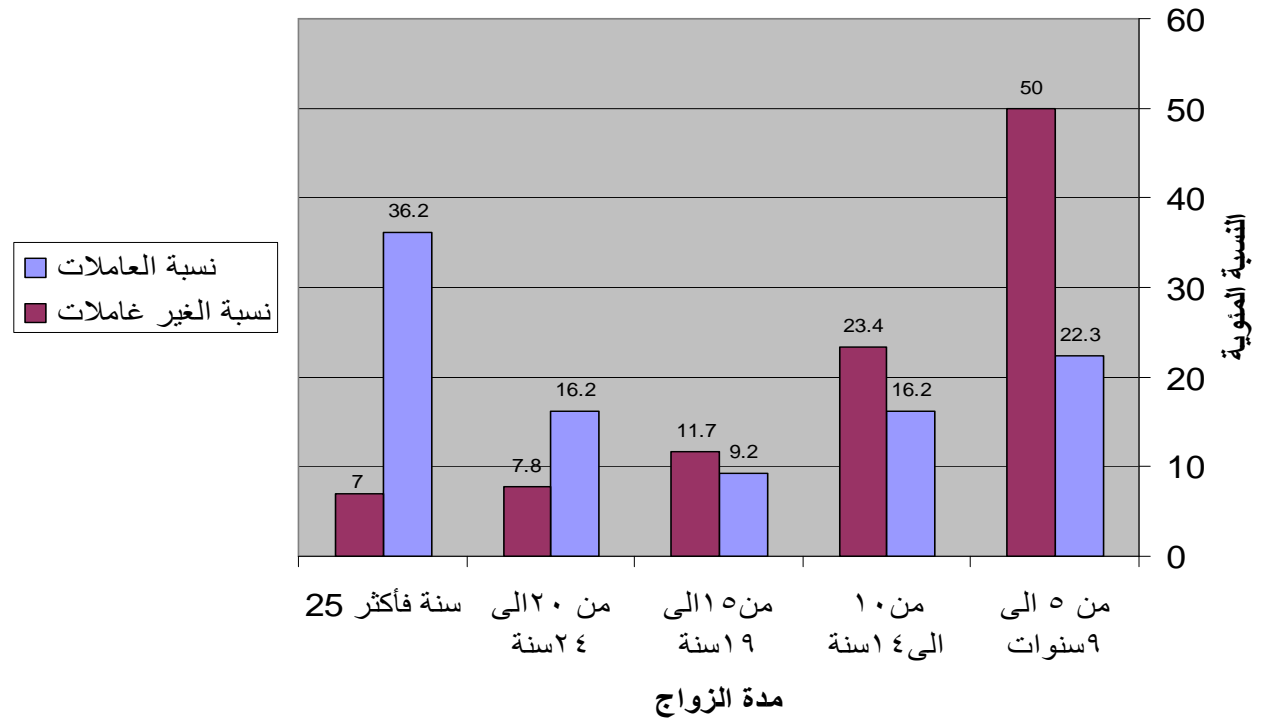

شكل(v) توزيـع عينـة البحث وفقا لمدة الزواج 


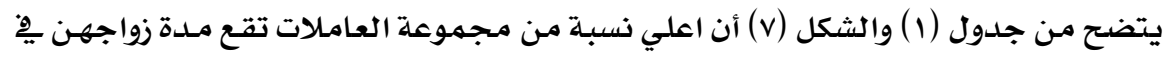

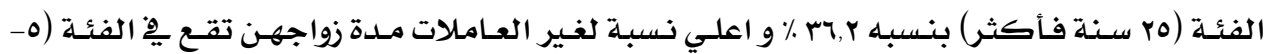

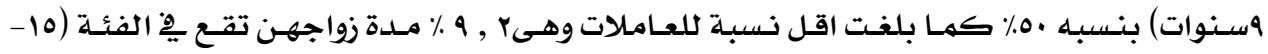

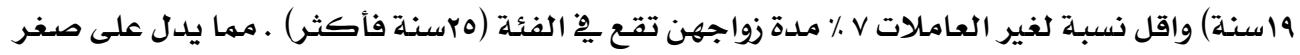

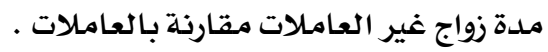
r. عمر الزوجين : مدهيز جدول ( r ) توزيع أفراد عينة البحث وفقاً لعمر الزوجين

\begin{tabular}{|c|c|c|c|c|}
\hline \multicolumn{2}{|c|}{ مـجموعة غير العـامـلات } & \multicolumn{2}{|c|}{ مجمهوعة العامـلات } & \multirow[b]{2}{*}{ العمر } \\
\hline النسبــة المئويـة & العدد & النسبــة المئويـة & العلدد & \\
\hline 1,9 & $r$ & $\cdot, \Lambda$ & 1 & اقل مـن ·r \\
\hline$r \cdot, v o$ & rV & $\varepsilon \leqslant, 10$ & ov & من •rالى \\
\hline$Y \wedge, \wedge 0$ & нی & re, ro & $\varepsilon \varepsilon$ & من ·سالى qr \\
\hline YY,V & r. & 17,1 & rY & من ·ع الىه؟ \\
\hline$I V, r$ & r & Y,VO & $\varepsilon$ & من +0 إلى 09 \\
\hline$\wedge, \varepsilon 0$ & 11 & 1,10 & r & أكثر مـن 7. \\
\hline$\% 1 \ldots$ & ir. & $\% 1 \ldots$ & IYA & المجهموع \\
\hline
\end{tabular}

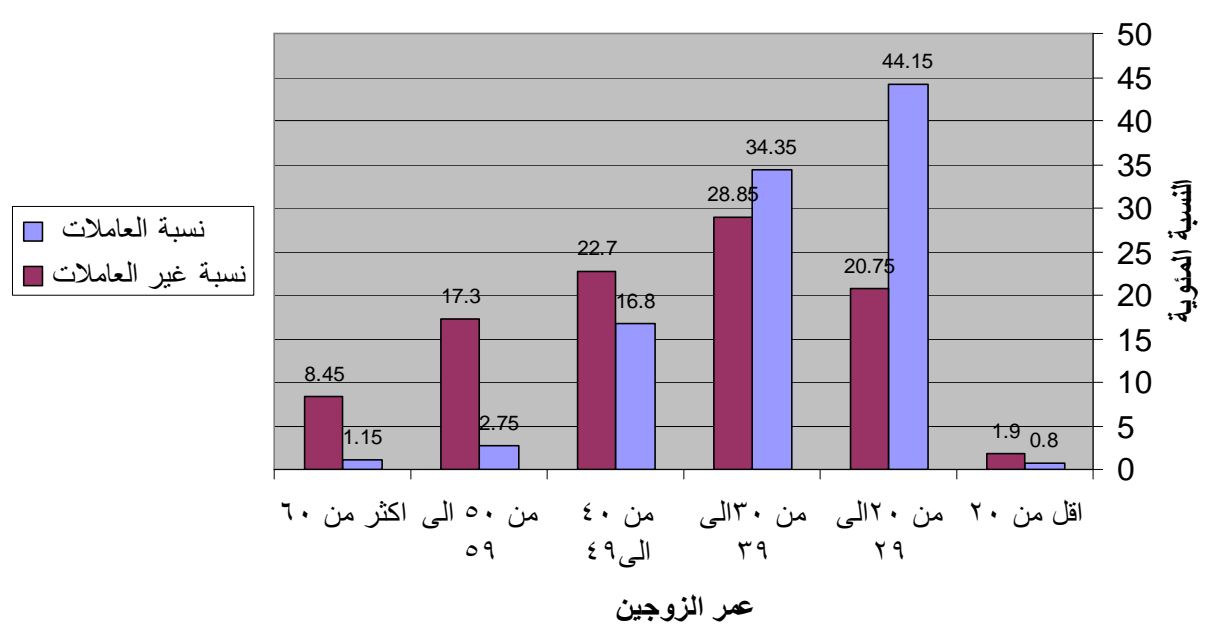

شكل (^) توزيع أفراد عينة البحث وفقاً لعمر الزوجين 


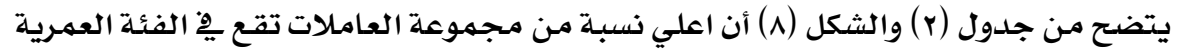

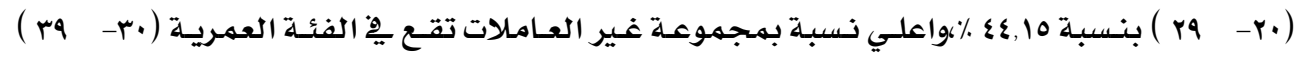

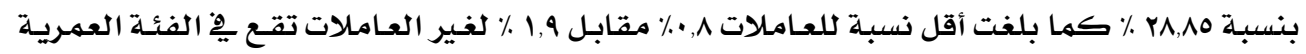

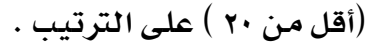

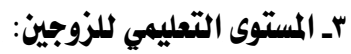
جدول ( r ) توزيع أفراد عينة البحث وفقاً للمستوى التعليمي للزوجين

\begin{tabular}{|c|c|c|c|c|}
\hline \multicolumn{2}{|c|}{ مجحموعة غير العامـلات } & \multicolumn{2}{|c|}{ مجموعة العـاملات } & \multirow{2}{*}{ المستوي التعليهي } \\
\hline النسبــة المئويـة & العددد & النسبــة المئويـة & العدد & \\
\hline س & $\varepsilon \varepsilon$ & - & - & أمى \\
\hline 19 & ro & $\varepsilon, r$ & 7 & الابتدائية \\
\hline ir & IV & $\varepsilon, V$ & 7 & المتوسطة \\
\hline rr & r. & $r r, \wedge 0$ & M & الثانويـة \\
\hline 11 & 18 & $\varepsilon \varepsilon, 10$ & ov & الجـامعة \\
\hline r & $r$ & $\mid r, 1$ & 17 & ماجستير \\
\hline$\cdot, \varepsilon$ & $\cdot, 0$ & $1 \cdot, 9$ & $1 \varepsilon$ & دكتوراه \\
\hline$\% 1 \ldots$ & Ir. & $\% 1 \ldots$ & $1 Y \Lambda$ & المجموع \\
\hline
\end{tabular}

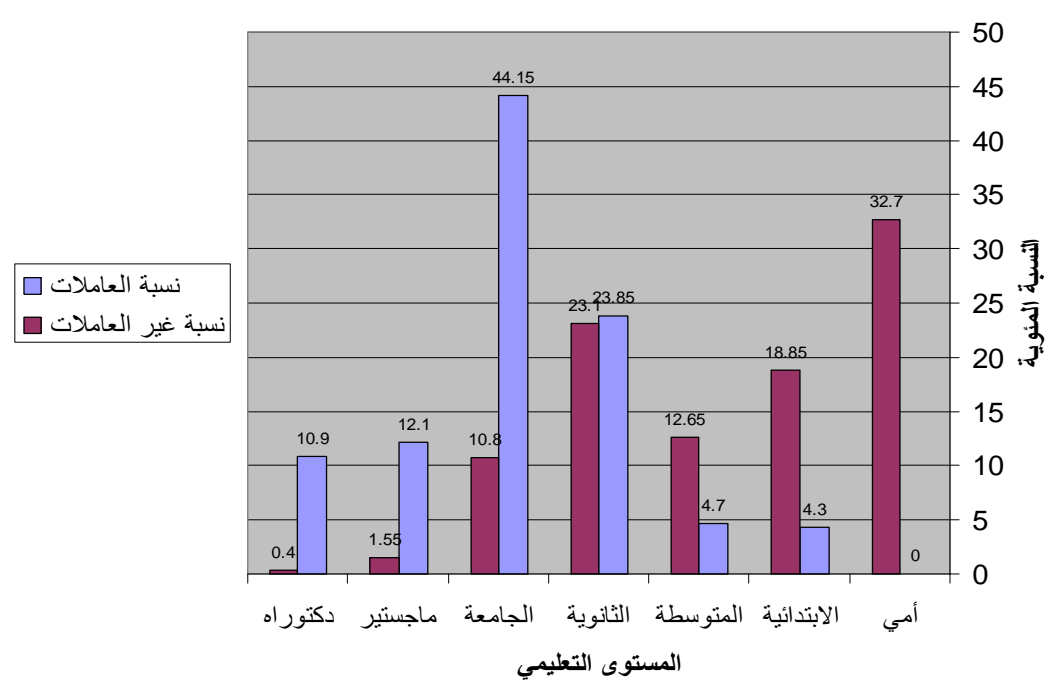

شكل (ه) توزيع أفراد عينة البحث وفقا" للمستوى التعليمي للزوجين

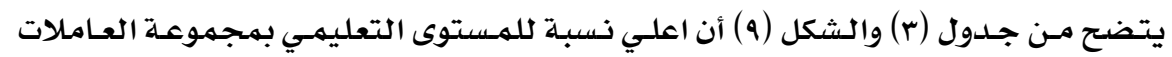

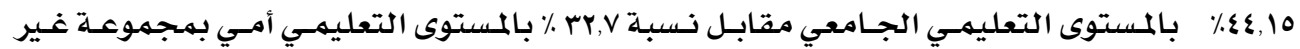




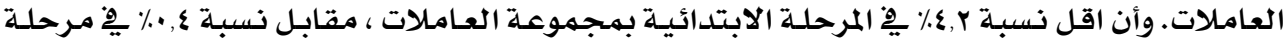
الدكتوراه بهـجموعة غير العاملات ـ مها يدل على ارتفاع المستوى التعليهي كـ مهنة الزوجين : 2

جلدول ( ع ) توزيـع أفراد عينـة البحث وفقاً لمهنـة الزوجين

\begin{tabular}{|c|c|c|c|c|}
\hline \multicolumn{2}{|c|}{ الزوجة } & \multicolumn{2}{|c|}{ الزوج } & \multirow[t]{2}{*}{ المهنة } \\
\hline النسبـة المئويـة & العددد & النسبـة المئويـة & العلدد & \\
\hline . & . & $r, r$ & $r$ & لا يعمل \\
\hline 1,7 & $r$ & 1,7 & $r$ & طالب \\
\hline 97,1 & Irr & 0. & $7 \varepsilon$ & حكومـة \\
\hline$\cdot, \Lambda$ & 1 & $Y \wedge, 1$ & T & عسكريـه \\
\hline 1,7 & r & $7, r$ & $\Lambda$ & خاص \\
\hline - & $\cdot$ & $1 \cdot, r$ & ir & أعمال حرة \\
\hline · & - & 1,7 & $r$ & متقاعد \\
\hline$\% 1 \ldots$ & IrA & $\% 1 \ldots$ & IrA & المجموع \\
\hline
\end{tabular}

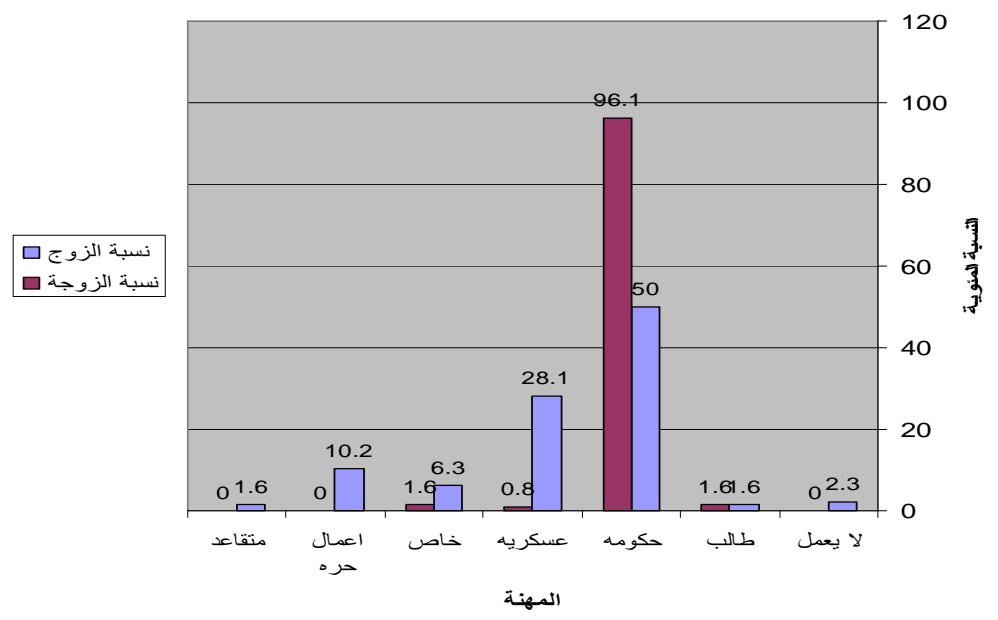

شكل ( • 1) توزيـع أفراد عينة البحث وفقا لمهنة الزوجين

يتضـح مـن جـدول (ع ) والشكل ( • ) أن أعلى نسبـة لمهنسة الازواج .0 ٪ وظـائف حكوميـة بينهـا

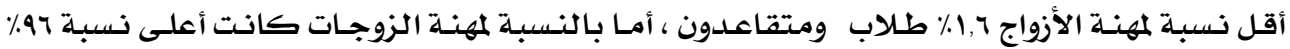
بالوظائف الحكومية وأقل نسبـة 7,1 ٪ طالبـات ونفس النسبـة للائي يعملن بالقطاع الخاص. 
جدول ( r ) توزيع أفراد عينة البحث وفقاً لمتوسط الدخل الشهري

\begin{tabular}{|c|c|c|}
\hline \multicolumn{2}{|c|}{ مجمهوعة العاملات } & \multirow{2}{*}{ الفئة } \\
\hline النسبة المئوية & العلدد & \\
\hline$\Lambda, 7$ & 11 & اقل من ...r ريال \\
\hline$r \cdot r$ & rt & من .... لأقل من .... \\
\hline rr,A & $\varepsilon r$ & من .... لأقل من ... \\
\hline $1 \xi, \Lambda$ & 19 & من .... لأقل من...... \\
\hline$\vee, \Lambda$ & 1. & من.... لأقل من .... \\
\hline 10,7 & $r$. & أكثر من ....11 ريال \\
\hline$\% 1 \ldots$ & $\mid Y \Lambda$ & المجموع \\
\hline
\end{tabular}

نسبة العاملات

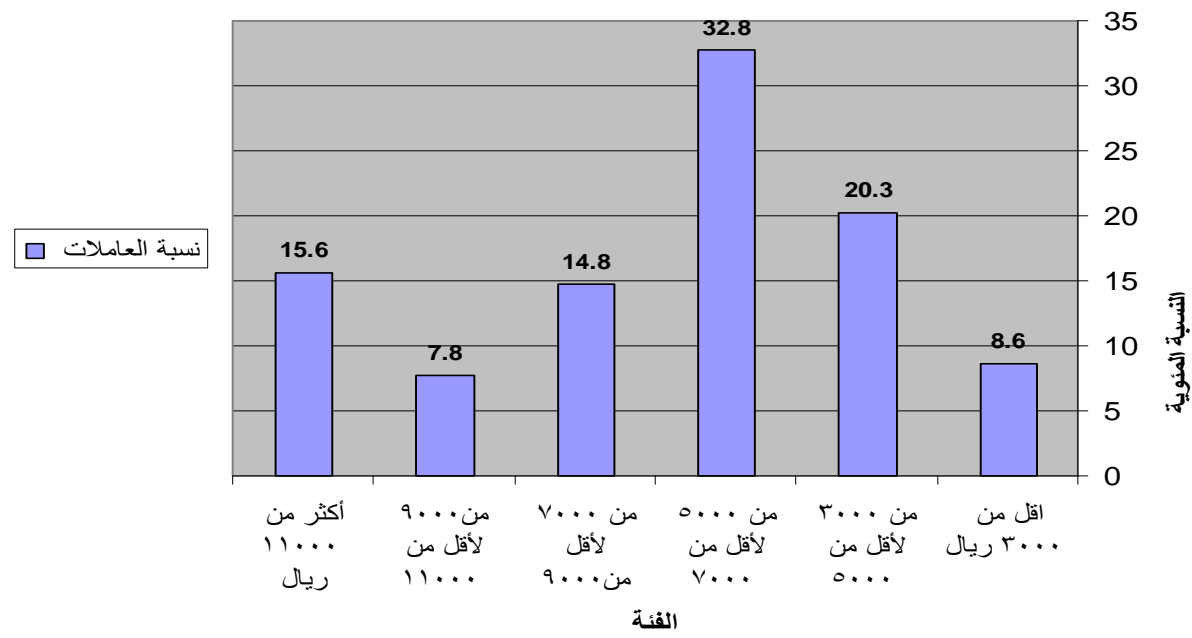

شكل (r) توزيع أفراد عينة البحث وفقاً لمتوسط الدخل الشهري

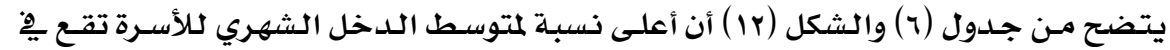

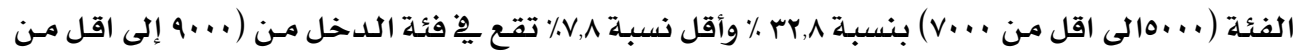

.(11... 


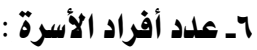

جدول ( 1 ) توزيع أفراد عينة البحث وفقاً لعدد أفراد الأسرة

\begin{tabular}{|c|c|c|c|c|c|c|}
\hline \multicolumn{3}{|c|}{ مجموعة غير العاملات } & \multicolumn{3}{|c|}{ مجموعة العاملات } & \multirow{2}{*}{ عدد أفراد الأسـرة } \\
\hline النسبـة المئوية & س & 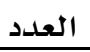 & النسبـة المئوية & س × ك5 & 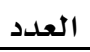 & \\
\hline$r$. & $1 \cdot 1$ & YV & $\{1, \varepsilon$ & YIY & or & $\varepsilon$ \\
\hline 10 & 90 & 19 & $Y O, \Lambda$ & 170 & r & 0 \\
\hline $\mathrm{V}, \mathrm{V}$ & 7. & 1. & 11 & $\Lambda \varepsilon$ & $1 \varepsilon$ & 7 \\
\hline $1 \cdot r$ & 91 & $1 \varepsilon$ & 9 & $\wedge \varepsilon$ & ir & $\checkmark$ \\
\hline v & VY & 9 & $\varepsilon$ & $\varepsilon \wedge$ & 7 & $\wedge$ \\
\hline 1. & $11 \mathrm{~V}$ & r & $\varepsilon$ & $0 \varepsilon$ & 7 & 9 \\
\hline 10 & 19. & 19 & r & r. & $r$ & 1. \\
\hline 10 & rYA & 19 & 9 & ir & 1 & أكثر من · 1 \\
\hline$\% 1 \ldots$ & 971 & ir. & $\% 1 \ldots$ & $7 \wedge 9$ & IrA & المجموع \\
\hline
\end{tabular}

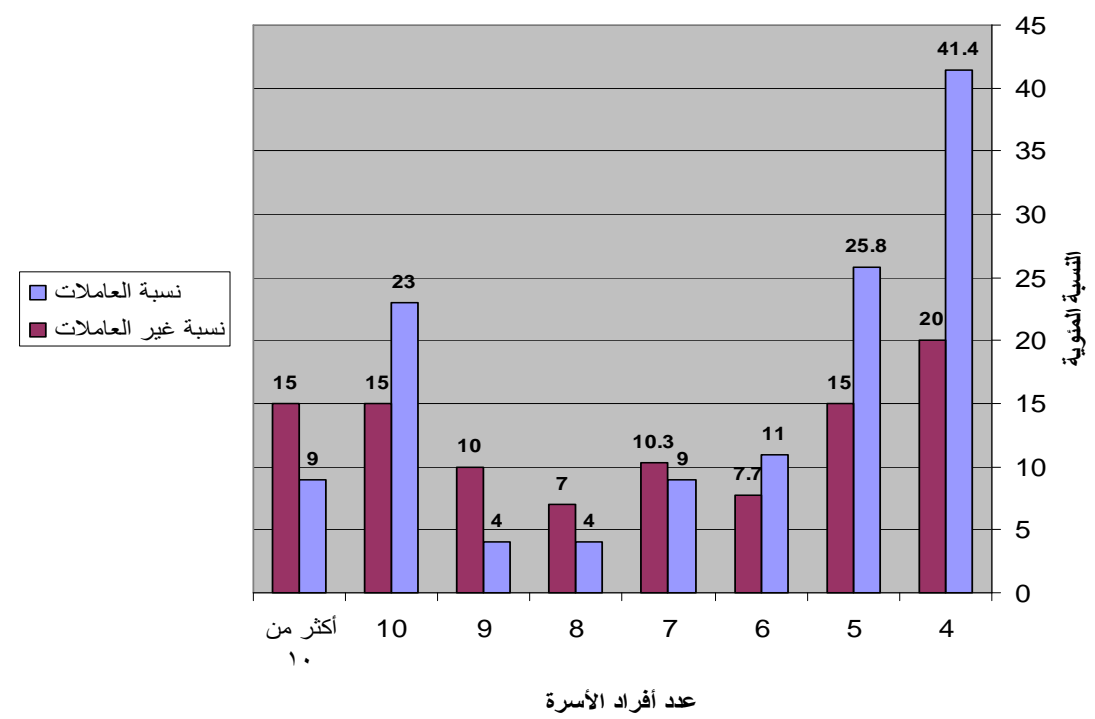

شكل ( \&1 ) توزيع آفراد العينة تبعا لعدد آفراد الاسرة الاسرة

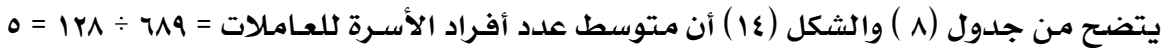

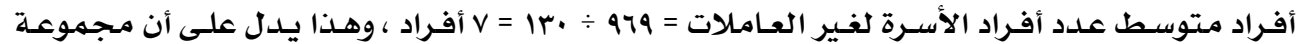

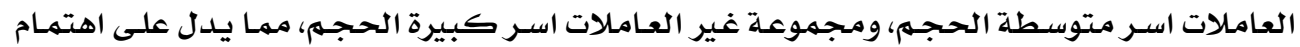




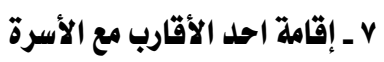

جدول ( 9 ) توزيع أفراد عينة البحث وفقاً لمتغير الإقامة مـع أ فراد الأسرة

\begin{tabular}{|c|c|c|c|c|}
\hline \multicolumn{2}{|c|}{ مجموعة غير العامـلات } & \multicolumn{2}{|c|}{ مـجموعة العامـلات } & البيان \\
\hline النسبة المئوية & العدد & النسبية المئوية & العددد & إقامـة احلد الأقارب مـع الأسـرة \\
\hline $17, r$ & rI & $\mathrm{V}, \Lambda$ & 1. & نعم \\
\hline$\Lambda \mu, \Lambda$ & 1.9 & $9 Y, Y$ & 111 & ע \\
\hline$\% 1 .$. & ir. & $\% 1 \ldots$ & IYM & المجموع \\
\hline
\end{tabular}

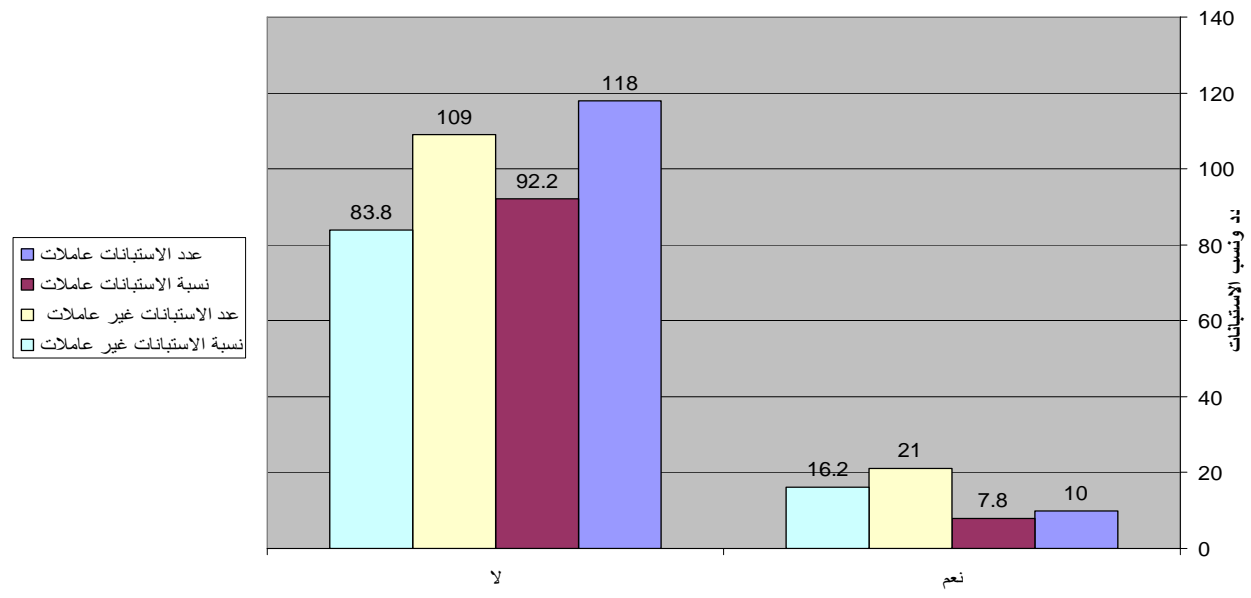

شكل (10) توزيع أفراد عينة البحث وفقاً لمتغير الإقامة مع أفراد الأسرة

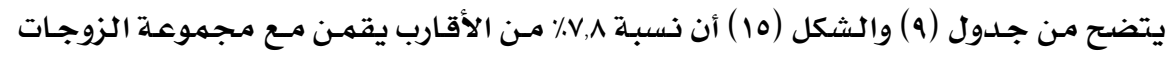

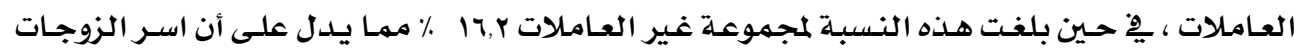

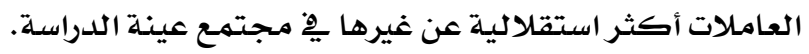
Aـ مساهمة الأقارب في مصروفات المنزل :

جدول ( ـ ) توزيع أفراد عينة البحث وفقا لدرجة مساهمة الأقارب ِِّ مصروفات المنزل

\begin{tabular}{|c|c|c|c|c|}
\hline \multicolumn{2}{|c|}{ مجموعة غير العاملات } & \multicolumn{2}{|c|}{ مجرموعة العـاملات } & \multirow{2}{*}{ مساهمـه الأقارب ِِّ مصروفات المنزل } \\
\hline النسبـة المئوية & العلدد & النسبــة المئويـة & العدد ال & \\
\hline Ir,r & 17 & $\varepsilon, V$ & 7 & نعم \\
\hline$\Lambda \mathrm{V}, \mathrm{V}$ & $11 \varepsilon$ & $90, r$ & IrY & ע \\
\hline$\% 1 \ldots$ & ir. & $\% 1 \ldots$ & IYN & المجموع \\
\hline
\end{tabular}




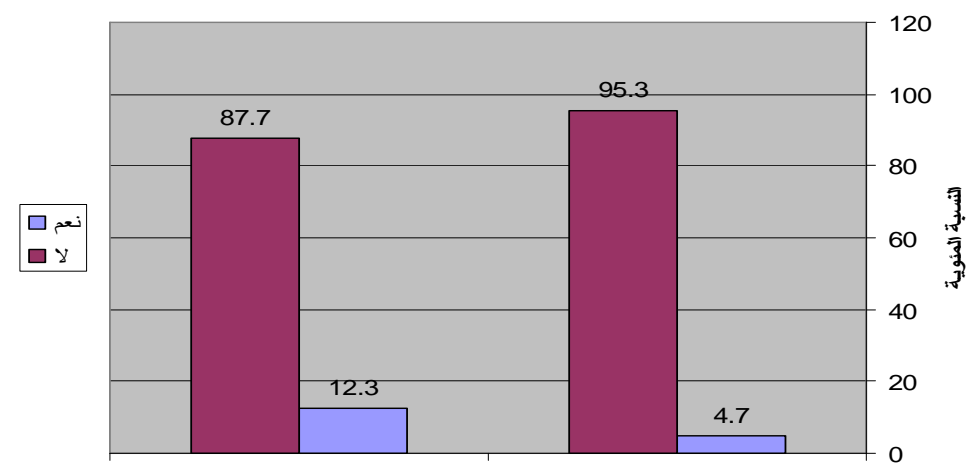

نسبة الغير عاملات

نسبة العاملات

مساهمة الأقارب في مصروفات المنزل

شكل (1 ) توزيـع أفراد عينـة البـحث وفقاً لدرجة مساهمـة الأقارب يْ مصروفات المنزل

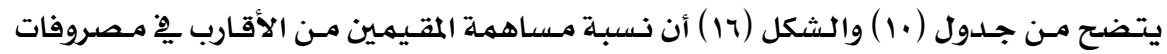

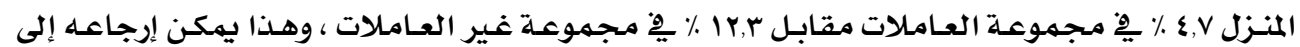

زيادة نسبـة المقيمـين من الأقارب بهـهموعة الزوجات غير العامـلات .

\section{9ـ ملدى مساهمة الزوجة في نققات الميشة :}

جدول ( 11 ) توزيع أفراد عينة البـحث وفقاً لمدى مسـاهمة الزوجة ِِِ نفقات المعيشة (دخل خاص)

\begin{tabular}{|c|c|c|c|c|}
\hline \multicolumn{2}{|c|}{ مجميوعة غير العامـلات } & \multicolumn{2}{|c|}{ مـجموعة العـاملات } & \multirow[b]{2}{*}{ المسـاهمـة يخ نفقات المنزل } \\
\hline النسبــة المئويـة & العدد & النسبــة المئويـة & العدد & \\
\hline$\Lambda, 7$ & 11 & $r 9, r$ & rл & نعم \\
\hline $91, \varepsilon$ & $11 \mathrm{~V}$ & $v \cdot, \Lambda$ & $9 r$ & 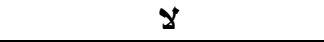 \\
\hline$\% 1 \ldots$ & IYA & $\% 1 \cdots$ & ir. & المجموع \\
\hline
\end{tabular}

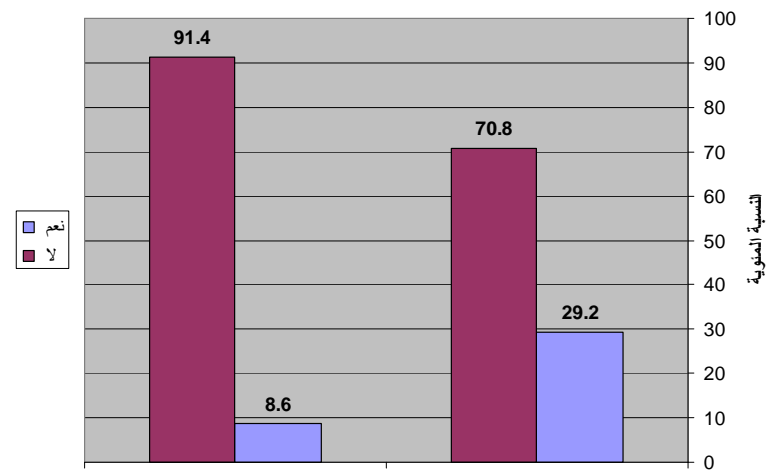

نسبة الغير عاملات

نسبة العاملات

المساهمة في نفقات المنزل

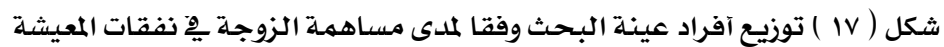




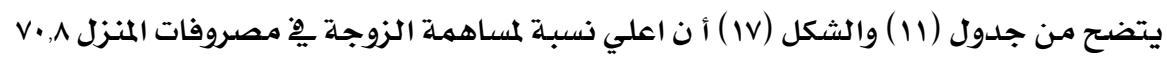

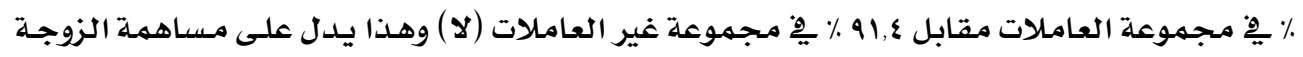

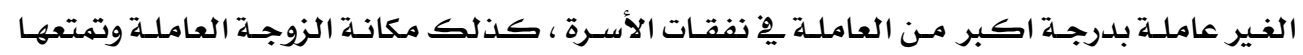

بالاستقلادلية .

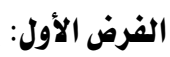

" تختلف درجة مشاركة الزوجين ـِّ اتخاذ القرارات الأسرية تبعاً لاختلاف مجال القرارات

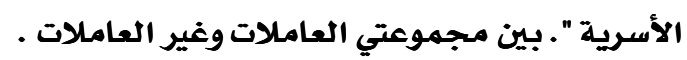

للتحقق من صحة هذا الفرض تم إيجاد قيمة (ت) T-Test للوقوف على دلالة الفـروق بـين

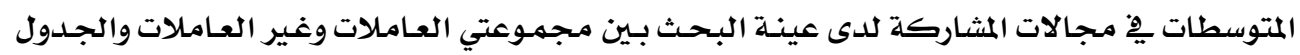

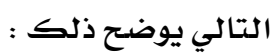

جدول (1)

الفروق بين المتوسطات حول مشاركة الزوجة لزوجها بٍِ اتخاذ القرارات الأسرية للعينة موضوع البحث

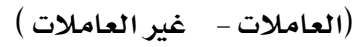

\begin{tabular}{|c|c|c|c|c|c|c|c|}
\hline \multirow{3}{*}{ 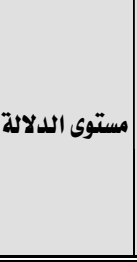 } & \multirow{3}{*}{ |ختبهة } & \multirow{3}{*}{ |درجة الحرية } & \multicolumn{4}{|c|}{ العينة } & \\
\hline & & & \multicolumn{2}{|c|}{ مجموعة غير العاملات } & \multicolumn{2}{|c|}{ 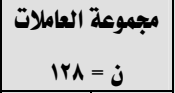 } & \multirow[b]{2}{*}{ جالات القرارات الأسرية } \\
\hline & & & الانحراف & المتوسط & الانحراف & المتوسط & \\
\hline$\cdot$, YYr & $1,1 Y r-$ & ror & $\cdot, 09$ & $r, \leqslant q$ & $\cdot, 0 \leq$ & $r, \diamond V$ & المشاركة في اتخاذ القرار في مجال رعاية الأبناء \\
\hline$\cdot, 047$ & $\cdot, 7 r \cdot-$ & ror & $\cdot, 70$ & r, r Y & $\cdot, 7$ & $r, r V$ & المشاركة في اتخاذ لقرار في المجالات الاقتصادية \\
\hline$\cdot, \uparrow \wedge \wedge$ & $\cdot, \varepsilon \cdot Y-$ & ror & צ & $r, r q$ & $\cdot, 04$ & $r, r r$ & المشاركة في اتخاذ القرار في المجالات الخاصة بإقامة الحفلات ) \\
\hline$* * *, \ldots 7$ & r,VYr- & ror & $\cdot, \mathrm{V} \varepsilon$ & $r, 17$ & $\cdot, 70$ & $r, \varepsilon \cdot$ & المشاركة في اتخاذ القرار في المجالات الخاصة باستقدام الخدم ) \\
\hline$\cdot, \varepsilon \vee r$ & $\cdot, V Y 1-$ & ror & $\cdot, \circ \mathrm{V}$ & $r, \leq 0$ & $\cdot, \leqslant 9$ & $r, 0 \cdot$ & المشاركة في اتخاذ القرار في المجالات الخاصة( بالزيارات العائلية ) \\
\hline$\cdot, \cdot \vee$ & $1, \vee \wedge \varepsilon-$ & ror & $\cdot, 7 \leqslant$ & r,rr & $\cdot, 7 \cdot$ & $r, \leqslant Y$ & المشاركة في اتخاذ القرار في المجالات الخاصة ( بإدارة شئون الأسرة \\
\hline
\end{tabular}

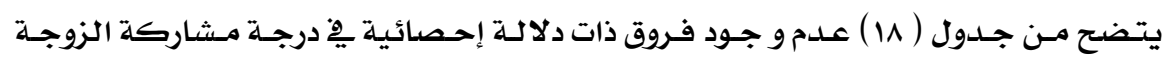

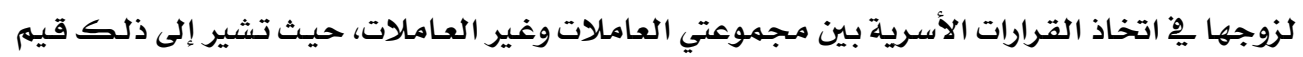

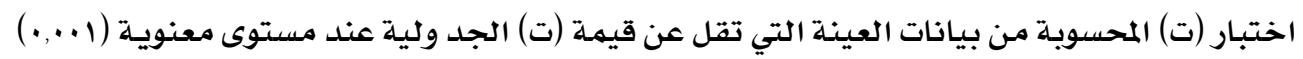

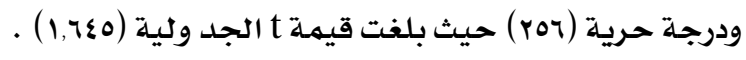

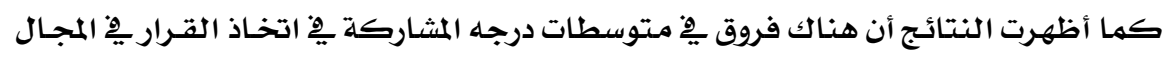

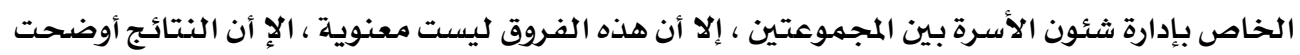


وجود فروق ذات دلالة إحصائية بـين ريـات الأسـر العـاملات وغير العـامـلات يِّ المجال الخـاص باستقدام

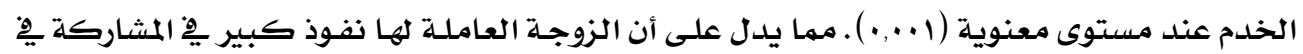

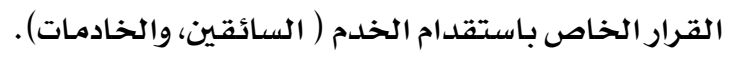

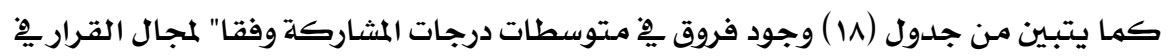

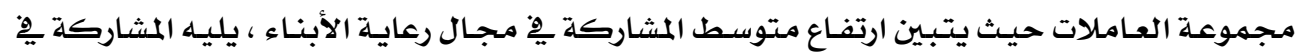

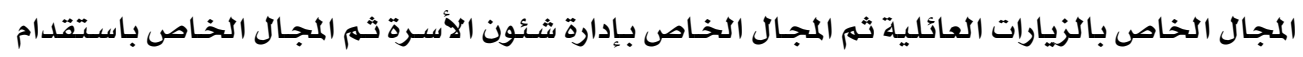

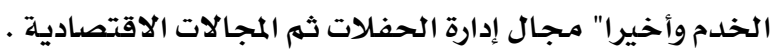

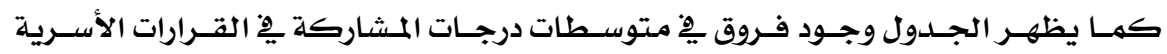

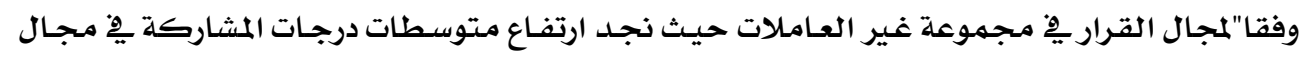

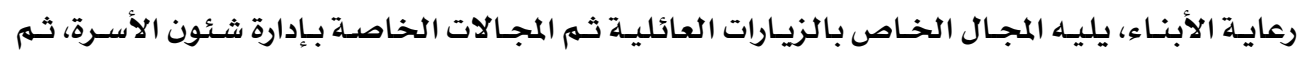

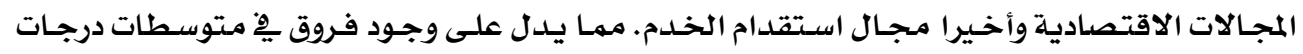

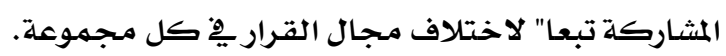

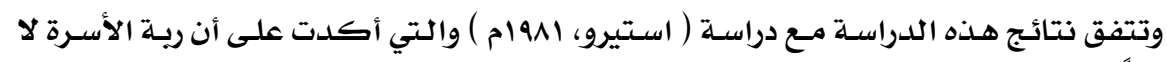

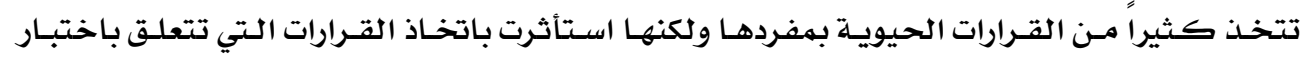

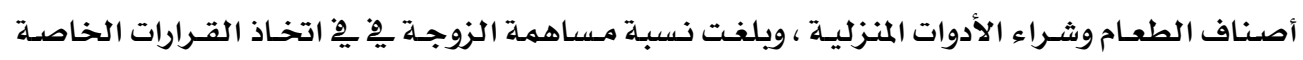

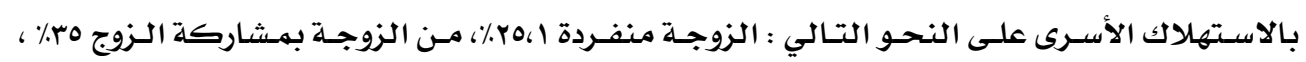

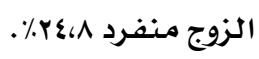

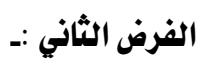

\section{" توجد فروق ذات دلالة إحصائية بين العاملات وغير العـاملات فِ أسـاليب اتخـاذ القـرارات}

\section{الأسرية بين الزوجين.}

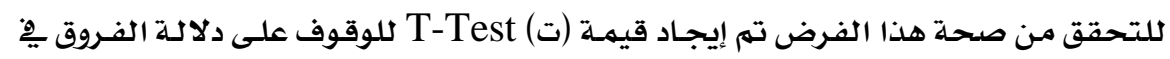

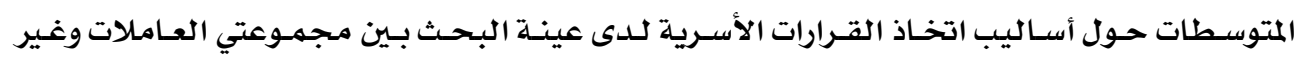

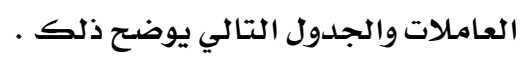


جدول (19)

الفروق ِِّ المتوسطات حول أساليب اتخاذ القرارات الأسرية ( ـِّمجموعتي العاملات - غير العاملات )

\begin{tabular}{|c|c|c|c|c|c|c|c|}
\hline \multirow{3}{*}{ 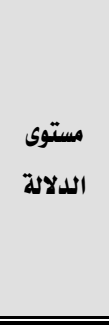 } & \multirow{3}{*}{ | قيمة } & \multirow{3}{*}{ | لدرجة } & \multicolumn{4}{|c|}{ 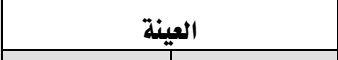 } & \multirow[t]{3}{*}{ 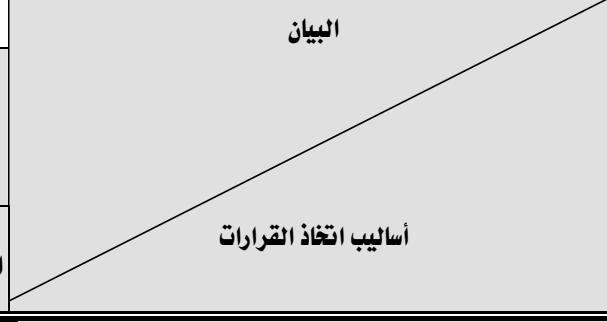 } \\
\hline & & & \multicolumn{2}{|c|}{ 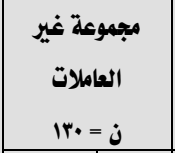 } & \multicolumn{2}{|c|}{ مجموعة العاملات } & \\
\hline & & & | الانحراف & |المتوسط & الالمعياري & المتوسط & \\
\hline., .94 & $1,7 \wedge 0$ & roT & $\cdot, \Lambda r$ & $1, \Lambda \mathrm{r}$ & $\cdot, \mathrm{v} \vee$ & 1,74 & اتخاذ القرار من جانب واحدلللهالزوجتلله دون مناقشة مع بقية أفراد الأسرة \\
\hline$* * *, \cdots$ & ะ,१५१- & roq & $\cdot, \uparrow$ & $r, \leqslant 0$ & $\cdot, \varepsilon$ & r, v & 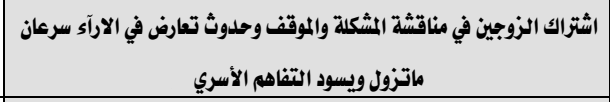 \\
\hline$\cdot, \wedge r q$ & $\cdot, r \cdot r_{-}$ & roT & $\cdot$, & $r, \leqslant \wedge$ & $\cdot, 7$ & r,o. & 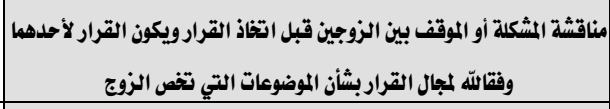 \\
\hline$\cdot, r \cdot r$ & $1, r \vee V_{-}$ & roq & $\cdot, 0 \wedge$ & $1, \Lambda r$ & $\cdot, \mathrm{v}_{0}$ & 1,94 & 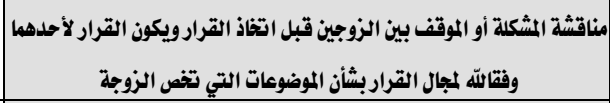 \\
\hline$* * *, \ldots$ & $\varepsilon, \varepsilon \cdot q$ & ror &., 01 & $r, V Y$ & $\cdot, \wedge 1$ & r, ro & أحاول التوفيق بين أهداف ورغبات أفراد الأسرة عند التعرض اشكلة ما \\
\hline & & 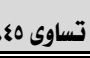 & 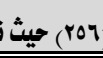 & 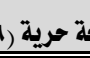 & 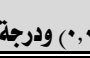 & 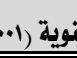 & تم احتساب قيمة (ت) الجد وليه عند مستوى معن \\
\hline
\end{tabular}

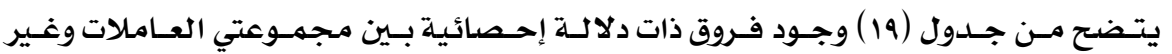

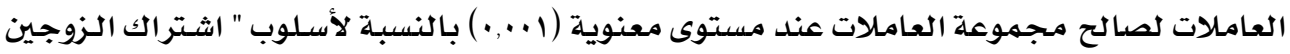

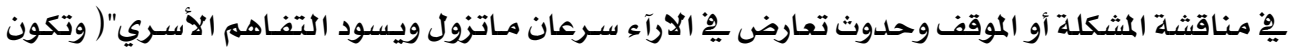
الزوجـة صاحبة القرار ) لصالح مجموعة العاملات ، حيث تشير قيمـة المتوسط الحسابي المرجح (r.VV)

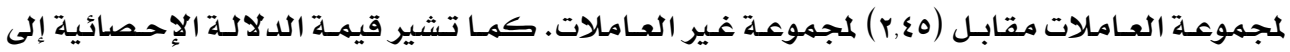

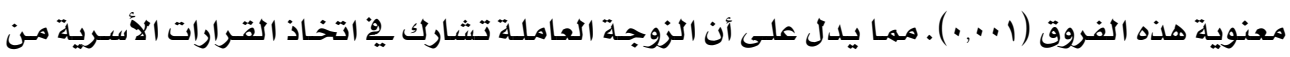

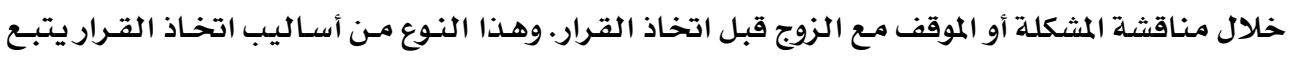

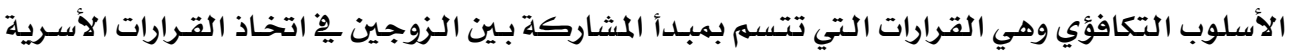
.(1971) McCrospy

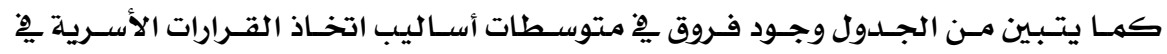

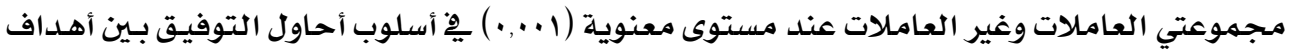

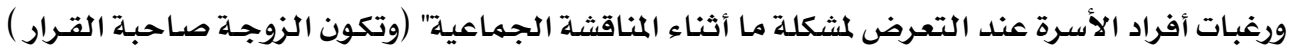

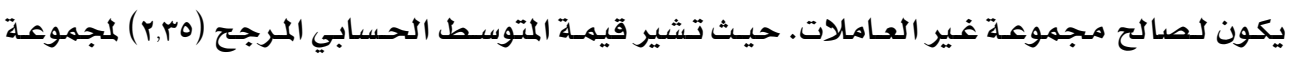

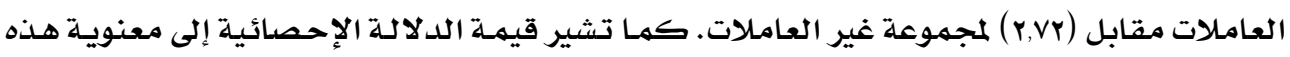

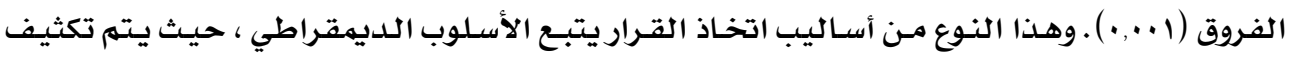


المناقشات حول المثكلة أو الموقف، مما يؤدي إلى نتـائج تحقق رغبـات جميـع أفراد الأسـرة( شـلبي وعبــا

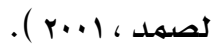

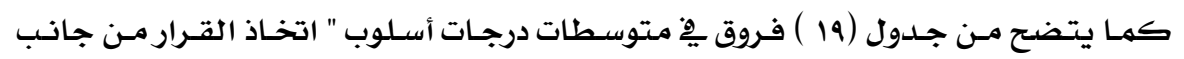

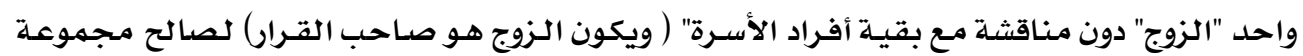

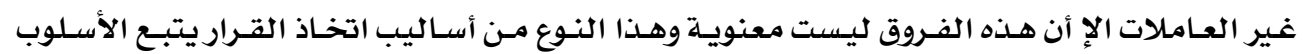

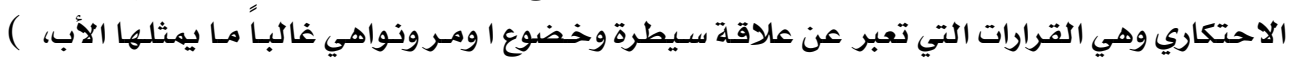
. McCrospy 1971)

كما يلاحظ أنه بالنسبـة لأسلوبي" مناقشة المشكلة أو الموقف بين الزوجين قبل اتخاذ القرار

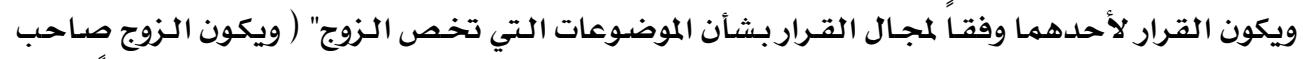

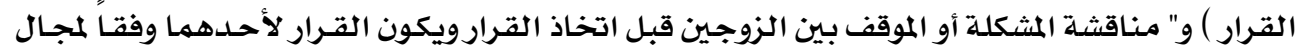

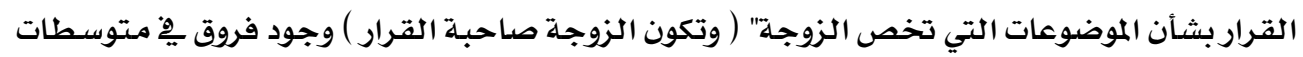

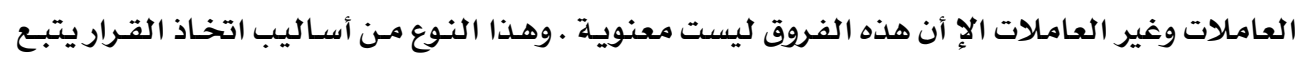

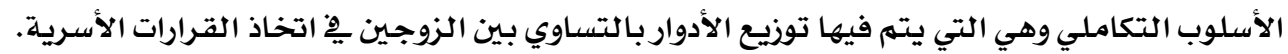
. McCrospy ، 1971)

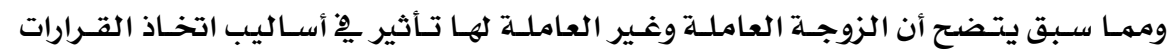

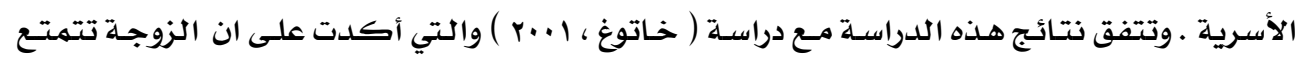

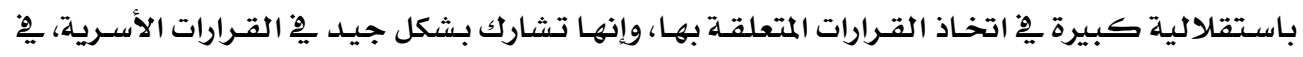

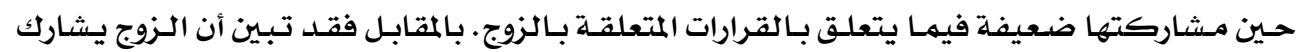

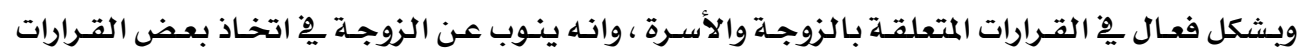

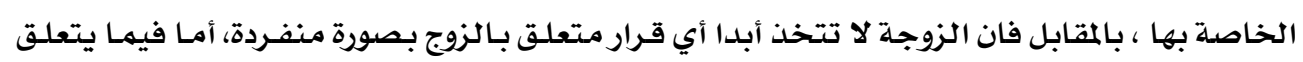

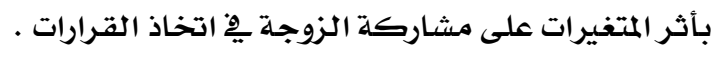
الثرض الثالث:

توجد علاقة ارتباطيه موجبة بين أبعاد الاستقرار الأسري وأساليب مشاركة الزوجة لزوجها

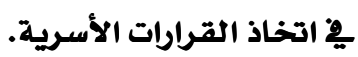

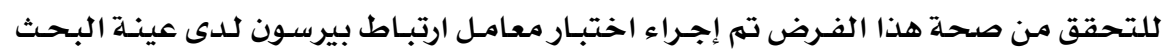

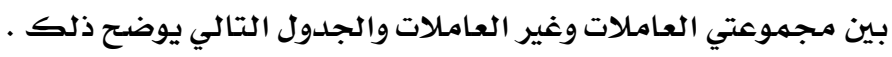




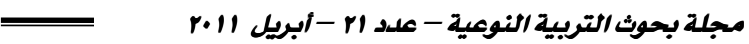




\section{توجد علاقة ارتباطيه بـين الاستقرار الأسـري بأبعـاده ودرجـة مشاركة الزوجـة لزوجها يـ}

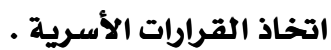

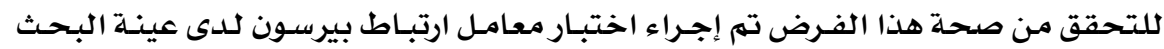

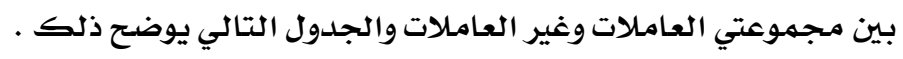

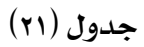

قيهم معاملات الارتبـاط بين الاستقرار الأسري ودرجة مشاركة الزوجة لزوجها يِّ القرارات الأسريـة

\begin{tabular}{|c|c|c|}
\hline \multicolumn{2}{|c|}{ درجة مشاركة الزوجة لزوجها يِ اتخاذ } & \multirow{3}{*}{ أبعاد الاستقرار الأسـري } \\
\hline \multicolumn{2}{|c|}{ ( مجموعة العـامـلات - غير العامـلات ) } & \\
\hline مستوى الدلالة & معامل الارتبـاط & \\
\hline$\cdot, \cdots$ & $* * *, 9 \vee \wedge$ & العلاقة بين الزوجين \\
\hline$\cdot, \cdots$ & $* * * 9 \wedge 1$ & علاقة الأب مـع الأبنـاء \\
\hline$\cdot, \cdots$ & $* * \cdot, 9 \wedge \Lambda$ & علاقة الأم مـع الأبنـاء \\
\hline$\bullet, \cdot$ & $* * .910$ & علاقة الأبنـاء مـع بعضهم البعض \\
\hline$\cdot, \cdots$ & $* * \cdot 9 \wedge \mathrm{V}$ & العلاقة بـين أفراد الأسـرة مـع بعضهم البعض \\
\hline$\cdot, \cdots$ & $* * .99 \varepsilon$ & دور الزوج يِّالأسـرة \\
\hline$\cdot, \cdots$ & $* * .977$ & دور الزوجـة يخ الأسـرة \\
\hline$\cdot, \cdots$ & $* * *, 971$ & عمل الزوجـة وأثرة ِِِ استقرار الأسـرة \\
\hline & معنويـة (1 (., • ) & خ * خ دال عند \\
\hline
\end{tabular}

يتضح من جدول (r) وجود علاقة ارتباطيه موجبة بين الاستقرار الأسري و درجة مشاركة

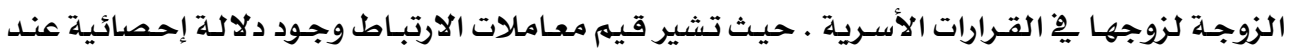

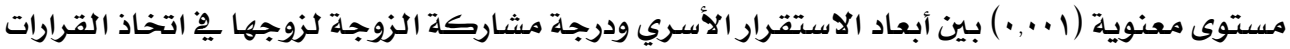

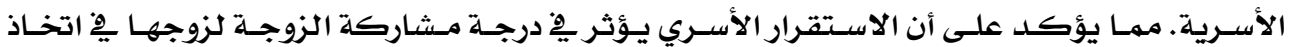

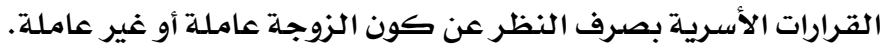

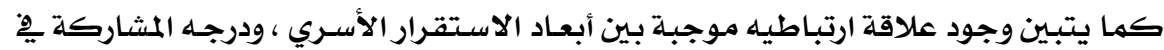

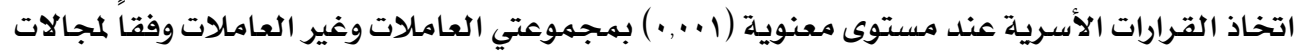

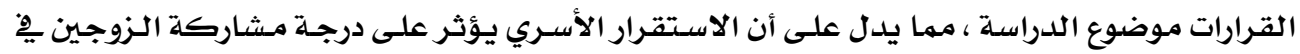

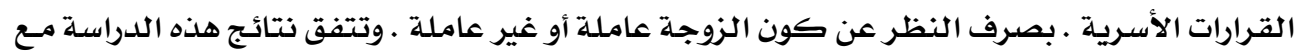

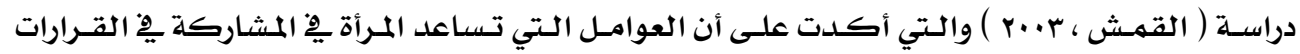


الأسـريـة مـن وجهـة نظـر النسـاء التفـاهم بـين الـزوجـين ، والثقــة بـالنفس ، وقوة الشخصـية ، والتوافق الاجتماعي بين الزوجي. الفرض الخامس:-

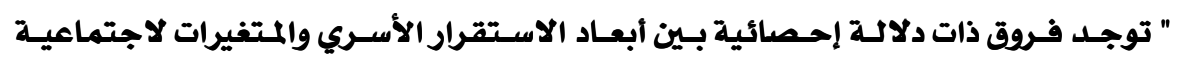

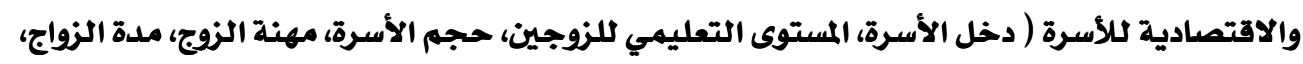

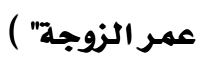

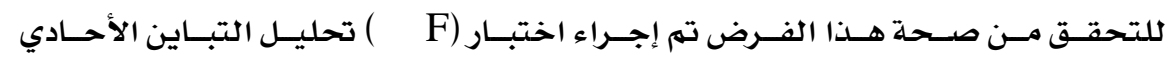

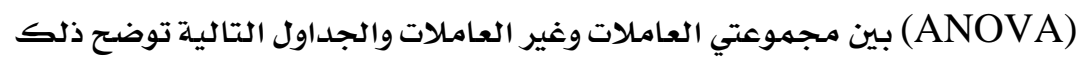

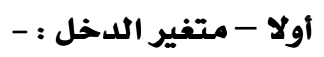

جدول (r) (r)

متوسطات أبعاد الاستقرار الأسـري وفقا" لمتغير الدخل

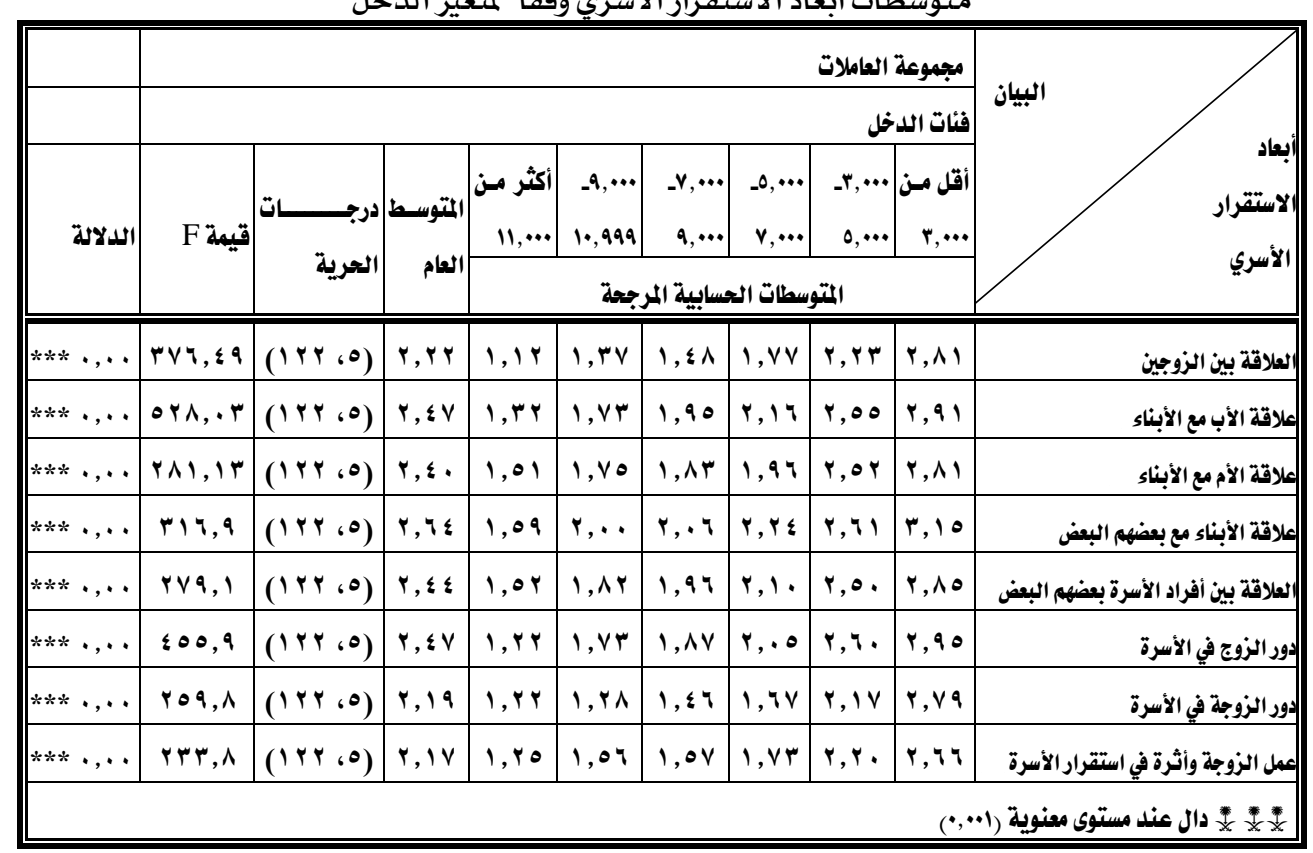

يتضح من جدول (rr) وجود فروق ذات دلالة إحصائية عند مستوى معنوية ( ا.... ) بين دخل

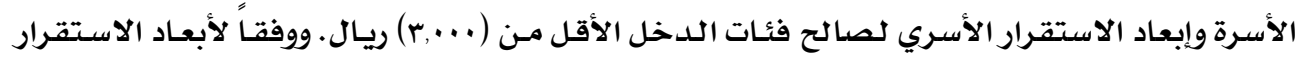

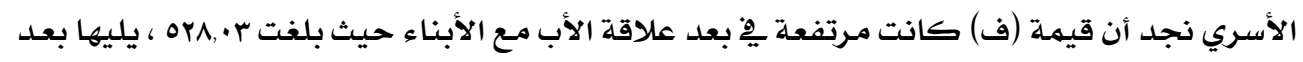

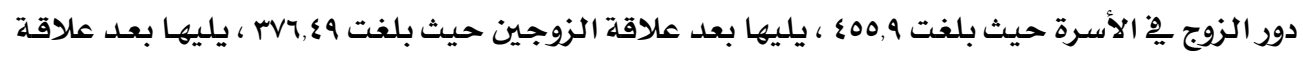

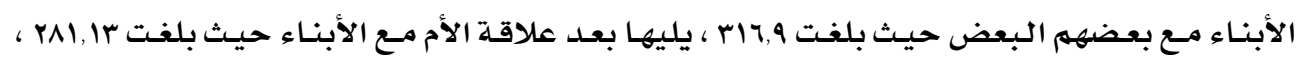




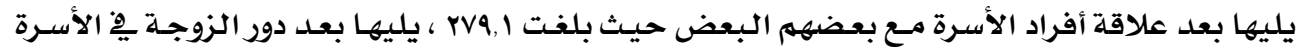

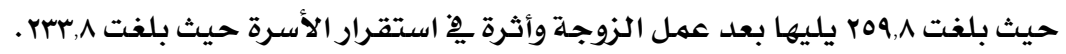

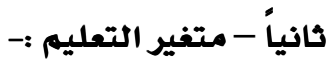

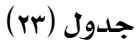

متوسطات أبعاد الاستقرار الأسري وفقا" لمتغير التعليم

\begin{tabular}{|c|c|c|c|c|c|c|c|c|c|c|c|}
\hline \multirow{4}{*}{ 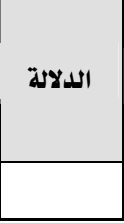 } & \multicolumn{10}{|c|}{ مجموعة العاملات } & \\
\hline & \multirow{3}{*}{$\mathrm{F}$} & \multirow{3}{*}{ الحرية } & \multirow{3}{*}{ |المتوسط } & \multirow{2}{*}{\multicolumn{7}{|c|}{ المتوستوى التمليمي للزوجين }} & \multirow{3}{*}{ الأ الاستقري } \\
\hline & & & & & & & & & & & \\
\hline & & & & | دكتوراه & |ماجستير & جامعي & ثانوية & متوسطة & | ابتدائي & أمي & \\
\hline$* * *, \ldots$ & $r V \leq, V \leq$ & $\left(\begin{array}{l}1 \\
1\end{array}\right.$ & Y, YY & 1,11 & $1, \leqslant 7$ & $r, . \wedge$ & $Y, \uparrow \Lambda$ & $r, १ \wedge$ & - & - & العلاقة بين الزوجين \\
\hline$* * *, \ldots$ & $r+1, \varepsilon \cdot$ & 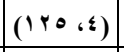 & $r, \leqslant v$ & $1, \leqslant r$ & 1,91 & $r, \leqslant r$ & $Y, \wedge \uparrow$ & r,१^ & - & - & علاقة الأب مع الأبناء \\
\hline$* * *, \ldots$ & $\mid r q, r r$ & $\left(\begin{array}{l}1 \\
Y\end{array}\right.$ & $r, \varepsilon$. & $1,0 \mathrm{~V}$ & $1, \wedge 1$ & $r, r \leq$ & $r, V \leqslant$ & $r, q 1$ & - & - & علاقة الأم مع الأبناء \\
\hline$* * *, \ldots$ & $19 \cdot, \leqslant 7$ & $\left(\begin{array}{l}1 \\
(\end{array}\right.$ & $r, T \leq$ & $1, v_{1}$ & $r, .0$ & r,o. & $r, 1 r$ & $r, r$. & - & - & علاقة الأبناء مع بعضهم البعض \\
\hline$* * *, \ldots$ & $1 \wedge 9, .0$ & $\left(\begin{array}{l}1 \\
(\end{array} 0 ، \mathrm{c}\right)$ & $r, \leqslant \leq$ & 1,7 & 1,94 & $r, r v$ & $r, V V$ & $r, १ \vee$ & - & - & العلاقة بين أفراد الأسرة بعضهم البعض \\
\hline$* * *, \ldots$ & 178, & $\left(\begin{array}{l}1 \\
Y\end{array}\right.$ & $r, \leqslant v$ & $1, \pi 4$ & 1,10 & $r, \leqslant r$ & $r, q r$ & $r, q 9$ & - & - & دور الزوج في الأسرة \\
\hline$* * *, \ldots$ & $r r \Delta, r q$ & $\left(\begin{array}{lll}1 & Y & 0\end{array}\right.$ & $r, 19$ & 1, r & $1, \leqslant 1$ & $r, .1$ & Y, 70 & $r, q 9$ & - & - & دور الزوجة في الأسرة \\
\hline$* * *, \ldots$ & $\mid \vee 7, \leqslant 1$ & $\left(\begin{array}{l}1 \\
\text { Y }\end{array}\right.$ & $1,1 \mathrm{~V}$ & $1, \pi \leq$ & 1,07 & $r, .0$ & Y,or & $r, \wedge r$ & - & - & عمل الزوجة وأثرة في الاستقرار الأسري \\
\hline
\end{tabular}

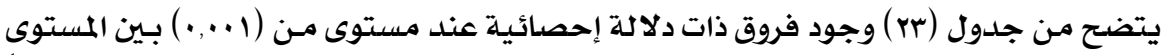

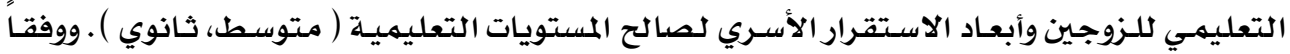

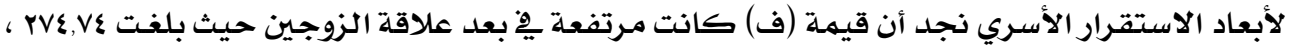

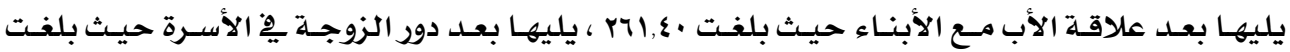

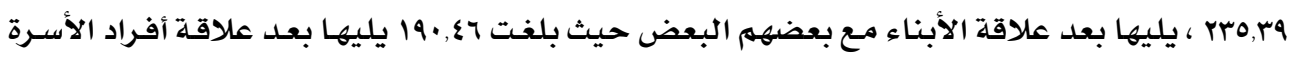

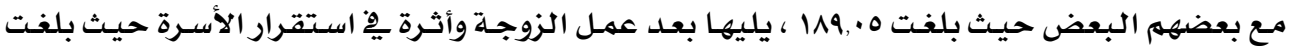

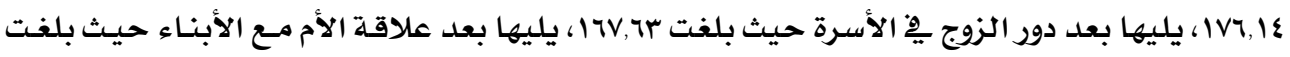


جدول (צ)

متوسطات أبعاد الاستقرار الأسـري وفقا لمتغير حجم الأسرة

\begin{tabular}{|c|c|c|c|c|c|c|c|c|c|c|c|c|}
\hline \multirow{4}{*}{ الإحصائية الدلة } & \multicolumn{11}{|c|}{ مجموعة العاملات } & \multirow{3}{*}{ البيان } \\
\hline & \multirow{3}{*}{ قيمة F } & \multirow{3}{*}{ الحرية } & \multirow{2}{*}{\multicolumn{9}{|c|}{ المتوسطات الحسابية المرجحة }} & \\
\hline & & & & & & & & & & & & \\
\hline & & & |التقوسط & أكثر من & 1. & 9 & $\wedge$ & $r$ & 1 & 0 & $\xi$ & حجم الأسرة \\
\hline$* * *, \ldots$ & rvq,o & $(1, r, \theta)$ & Y,YY & - & - & $1,1 \mathrm{r}$ & $1, r v$ & $1, \leqslant \wedge$ & $1, \vee v$ & $r, Y r$ & $r, \Lambda_{1}$ & العلاقة بين الزوجين \\
\hline$* * *, \ldots$ & OrA, $\cdot r$ & $(1 Y Y, 0)$ & $Y, \leqslant V$ & - & - & $1, r Y$ & $1, V Y$ & 1,90 & $r, 17$ & $r, \infty$ & $r, 9)$ & علاقة الأب مع الأبناء \\
\hline$* * *, \ldots$ & $r \wedge 1,1 r$ & $(I Y Y, 0)$ & Y,, . & - & - & 1,01 & $1, v 0$ & $1, \wedge r$ & 1,97 & $r, \Delta r$ & $r, \wedge 1$ & علاقة الأم مع الأبناء \\
\hline$* * *, \ldots$ & riq, & $(1, Y, 0)$ & Y, & - & - & 1,09 & $r, \ldots$ & $r, .7$ & $r, r \leqslant$ & $r, \sqcap$ & $r, 10$ & علاقة الأبناء مع بعضهم البعض \\
\hline$* * *,, \ldots$ & rva, $1 \leq$ & $(I Y r, 0)$ & $Y, \leqslant \leq$ & - & - & $1,0 Y$ & $1, \wedge r$ & 1,97 & $r, 1 \cdot$ & $r, 0$. & $r, \wedge 0$ & العلاقة بين أفراد الأسرة بعضهم البعض \\
\hline$* * *, \ldots$ & $\leq 00,9$ & $(I Y Y, 0)$ & $r, r \leq$ & - & - & $1, r Y$ & $1, V r$ & $1, \wedge \mathrm{V}$ & $r, .0$ & $r, Y$. & $r, 90$ & دور الزوج في الأسرة \\
\hline$* * *, \ldots$ & $r \diamond ৭, \wedge$ & $(I Y Y, 0)$ & r, 19 & - & - & $1, r Y$ & $1, Y \wedge$ & $1, \leqslant 7$ & $1,7 \mathrm{~V}$ & $r, I V$ & $r, v a$ & دور الزوجة في الأسرة \\
\hline$* * *, \ldots$ & ( & $(1, r, 0)$ & r, IV & - & - & $1, r_{0}$ & 1,07 & $1,0 \mathrm{~V}$ & $1, \vee r$ & $r, r \cdot$ & Y,Y & عمل الزوجة ودورها في الاستقرار الأسري \\
\hline
\end{tabular}

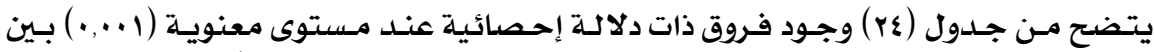

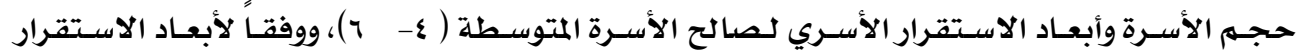

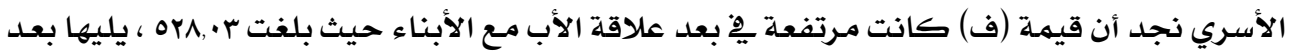

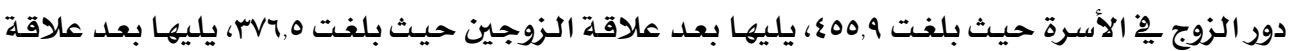

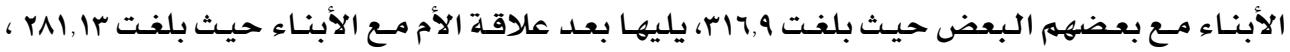

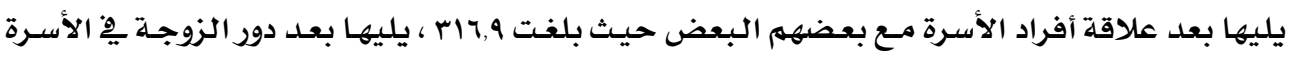

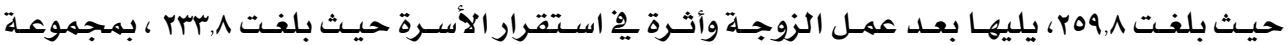


جدول (ro)

متوسطات أبعاد الاستقرار الأسري وفقاً لمتغير مهنـة الزوج

\begin{tabular}{|c|c|c|c|c|c|c|c|c|c|c|c|}
\hline \multirow{4}{*}{ مستوى الدلالة } & \multicolumn{10}{|c|}{ مجموعة العاملات } & \multirow{4}{*}{ 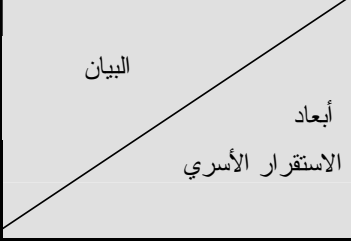 } \\
\hline & \multirow{3}{*}{$\mathrm{F}$} & \multirow{3}{*}{ درجات } & \multirow{3}{*}{ العتوسط } & \multicolumn{7}{|c|}{ مهنة الزوج } & \\
\hline & & & & \multicolumn{7}{|c|}{ المتوسطات الحسابية المرجحة } & \\
\hline & & & & متقاعد & |أعمال & خاص & عسكرية & 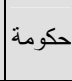 & 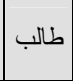 & بعمل & \\
\hline$* * *, \ldots$ & $1 \leq r, 9$ & 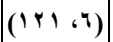 & Y, Y r & $1, \ldots$ & $1, r \mu$ & $1, \leqslant \leqslant$ & r,q. & ץ, ^ & $r, \cdots$ & $r, \ldots$ & العلاقة بين الزوجين \\
\hline$* * *, \ldots$ & ץrq, & 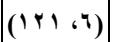 & $Y, £ V$ & $1, \cdot r$ & $1,0 Y$ & 1,91 & r, rV & $Y, \wedge \leq$ & $r, \ldots$ & $r, \ldots$ & علاقة الأب مع الأبناء \\
\hline$* * *, \ldots$ & $179, \cdot r$ & $\left(\begin{array}{llll}1 & Y & 1 & 6\end{array}\right)$ & r, \&. & 1,17 & 1,70 & $1, \vee 9$ & $r, 10$ & Y,V & $r, \ldots$ & $r, \ldots$ & علاقة الأم مع الأبناء \\
\hline$* * *, \ldots$ & YIY,I & 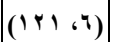 & Y, Y & $1,1 \mathrm{~V}$ & 1,11 & $r, .0$ & r,r & $r, \cdot T$ & $r, r \cdot$ & $r, r$. & علاقة الأبناء مع بعضهم البعض \\
\hline$* * *, \ldots$ & $19 \cdot, 9$ & 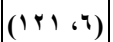 & $Y, \leq \leq$ & 1,1 & $1, v \cdot$ & 1,94 & r, r & $\curlyvee, \vee \wedge$ & $r, \ldots$ & $r, \ldots$ & العلاقة بين أفر اد الأسرة بعضهم البعض \\
\hline$* * *, \ldots$ & $197, Y$ & 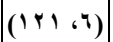 & $r, £ V$ & $1, \ldots$ & $1, \leq \leqslant$ & 1,10 & r, r & r,q. & $r, \ldots$ & $r, \ldots$ & دور الزوج في الأسرة \\
\hline$* * *, \ldots$ & Irr,r & 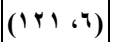 & $r, 19$ & 1,14 & $1, r_{0}$ & $1, \leqslant 1$ & $1, \wedge 1$ & Y,Y & $r, \ldots$ & $r, \ldots$ & دور الزوجة في الأسرة \\
\hline$* * *, \ldots$ & Irv, & 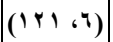 & r,IV & $1, \cdots$ & $1, \leqslant 1$ & 1,07 & $1, \wedge \wedge$ & r,०० & $r, \ldots$ & $r, \ldots$ & عمل الزوجة وأثرة في استقرار الأسرة \\
\hline
\end{tabular}

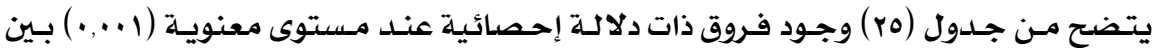

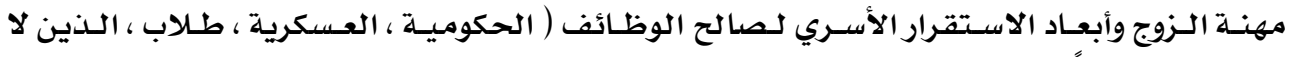

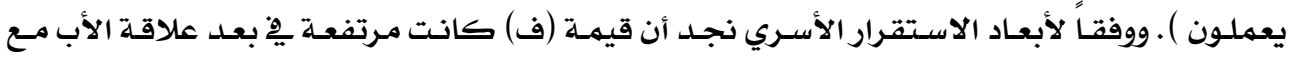

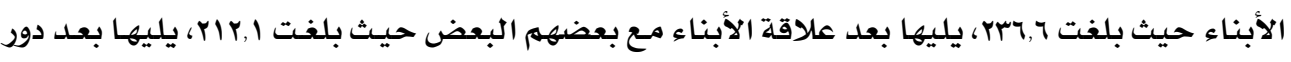

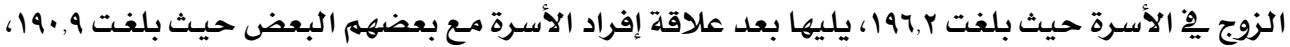

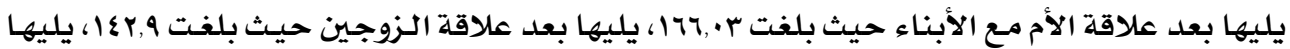

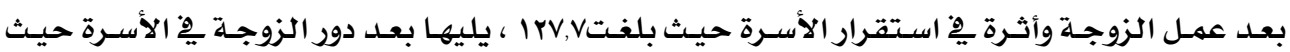

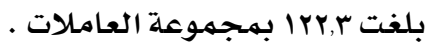


خامساً - متغير مدة الزواج :-

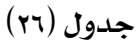

متوسطات أبعاد الاستقرار الأسـري وفقا لمتغير مدة الزواج

\begin{tabular}{|c|c|c|c|c|c|c|c|c|c|}
\hline \multirow{3}{*}{ الإحصائية } & \multicolumn{8}{|c|}{ مجمو عة العاملات } & \multirow{3}{*}{ أبعاد الاستقر ار الأسري } \\
\hline & \multirow[b]{2}{*}{ ق قيمة F F } & \multirow{2}{*}{ درجات } & \multicolumn{6}{|c|}{ مدة الزو اج } & \\
\hline & & & المتوسط & فأكثر & $\begin{array}{l}-r . \\
\text {. }\end{array}$ & $\begin{array}{l}-10 \\
9 \text { (سنة }\end{array}$ & $\mid$\begin{tabular}{|l}
-1. \\
\& اسنة
\end{tabular} & $\begin{array}{l}-0 \\
\text { 9سنة }\end{array}$ & \\
\hline$* * *, \ldots$ & $r i v, 0$ & $(1 Y r, \varepsilon)$ & r, r & 1,1 & $1, r \wedge$ & 1,07 & $r, \cdot V$ & $r, V \leqslant$ & العلاقة بين الزوجين \\
\hline$* * * \cdot, \ldots$ & $\leqslant 01, \wedge$ & $(1 Y r, \varepsilon)$ & $r, \leqslant \vee$ & $1, r \wedge$ & $1, \vee \wedge$ & $r, \cdot r$ & r, ६ & $r, \wedge \vee$ & علاقة الأب مع الأبناء \\
\hline$* * *, \ldots$ & ror, $\varepsilon$ & $(1, r, \varepsilon)$ & $r, \varepsilon$. & $1, \leqslant 9$ & $1, v_{0}$ & $1, \wedge \wedge$ & $r, r r$ & $Y, \vee q$ & علاقة الأم مع الأبناء \\
\hline$* * *, \cdots$ & or^,r & $(1, r, \varepsilon)$ & Y, & 1,04 & $r, \ldots$ & r,11 & $Y, \leqslant Y$ & $r, 11$ & علاقة الأبناء مع بعضهم البعض \\
\hline$* * *, \ldots$ & $r r \leq, v$ & $(1 Y r, \varepsilon)$ & $r, \leqslant \leqslant$ & $1, \leqslant 9$ & $1, \wedge 0$ & $r, \ldots$ & $r, r_{0}$ & $r, \wedge r$ & العلاقة بين أفر اد الأسرة بعضهم البعض \\
\hline$* * *, \ldots$ & $04 r, r$ & $(1 Y r, \varepsilon)$ & $r, \leqslant \vee$ & 1,11 & $1, v \leqslant$ & 1,91 & r, ६ $\cdot$ & $r, 9 r$ & دور الزوج في الأسرة \\
\hline$* * *, \ldots$ & $197, r$ & $(I Y r ، \varepsilon)$ & r, 19 & $1, r_{1}$ & $1, r 1$ & $1,0 \leqslant$ & 1,99 & $r, v_{1}$ & دور الزوجة في الأسرة \\
\hline$* * *, \ldots$ & $r \circ 0, .0$ & $(1 Y r, \varepsilon)$ & $r, I V$ & $1, r_{1}$ & 1,04 & 1,09 & $r, \cdot r$ & $r, T$ & عمل الزوجة ودور ها في الاستقرار الأسري \\
\hline
\end{tabular}

يتضح من جدول (بr) وجود فروق ذات دلالة إحصائية عند مستوى معنوية (1 ..,.) بين مدة

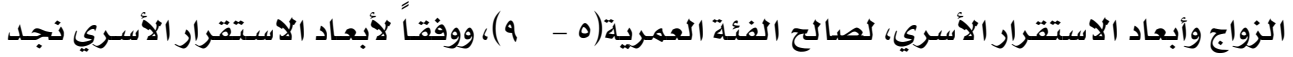

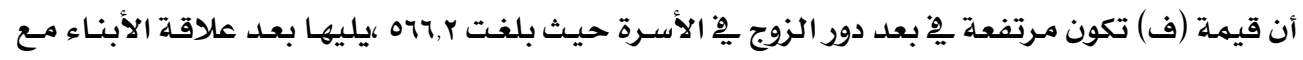

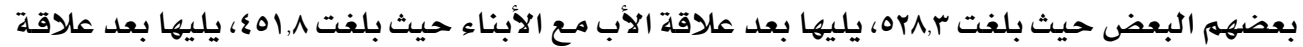

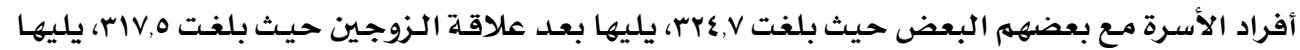

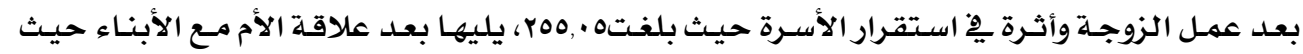

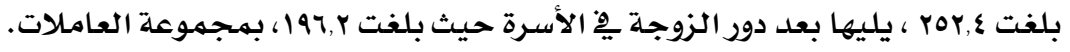




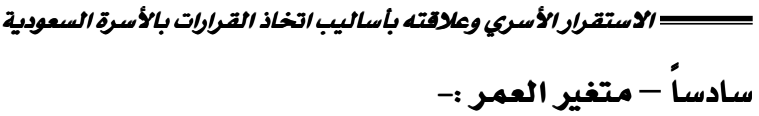

جدول رقم (rv)

\begin{tabular}{|c|c|c|c|c|c|c|c|c|c|c|}
\hline \multirow{4}{*}{ 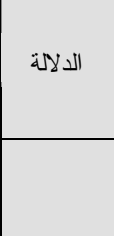 } & \multicolumn{9}{|c|}{ مجموعة العاملات } & \multirow{3}{*}{ البيان } \\
\hline & \multirow{3}{*}{$\mathrm{F}$} & \multirow{3}{*}{ درجات } & \multicolumn{7}{|c|}{ عمر الزوجة } & \\
\hline & & & \multicolumn{7}{|c|}{ المتوسطات الحسابية المرجحة } & \\
\hline & & & العام & |أكثر من . اسنة & 9. & 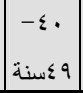 & و qrاسنة & $\begin{array}{c}-r . \\
\text {. }\end{array}$ & | أقل من & الاستقرار الأسري \\
\hline$* * *, \ldots$ & IAr,T & 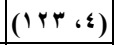 & Y,rY & - & $1, \ldots$ & $1, \mathrm{r} \wedge$ & $1, \wedge \varepsilon$ & $\curlyvee, \uparrow \wedge$ & $r, \ldots$ & العلاقة بين الزوجين \\
\hline$* * *, \ldots$ & $r v \leq, 1$ & (IY & $r, \leqslant V$ & - & $1, \cdot r$ & $1, \pi r$ & Y, r r & $\curlyvee, \wedge \leqslant$ & $r, \ldots$ & علاقة الأب مع الأبناء \\
\hline$* * *, \ldots$ & $r \leqslant r, r$ & 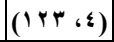 & Y, \&. & - & 1,18 & 1,79 & $r, 1$. & $r, v \uparrow$ & $r, \ldots$ & علاقة الأم مع الأبناء \\
\hline$* * *, \cdots$ & $r \leq q, \varepsilon$ & $(I Y r ، \Omega)$ & Y, $\{$. & - & $1,1 \mathrm{~V}$ & $1, \wedge \vee$ & $r, r V$ & $r, .0$ & $r, r \cdot$ & علاقة الأبناء مع بعضهم البعض \\
\hline$* * *, \ldots$ & $r \leq 7,1$ & 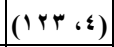 & $r, \varepsilon \leq$ & - & 1,1 . & $1, V_{4}$ & $r, 1 \Lambda$ & $r, v q$ & $r, \ldots$ & العلاقة بين أفر اد الأسرة بعضهم البعض \\
\hline$* * *, \ldots$ & $r \leq 7,0$ & $(I Y r ، \varepsilon)$ & $r, \leqslant V$ & - & $1, \ldots$ & 1,00 & $r, I V$ & $r, q$. & $r, \ldots$ & دور الزوج في الأسرة \\
\hline$* * *, \ldots$ & IVr,q & $(I Y r, \varepsilon)$ & $r, 19$ & - & $1,1 r$ & $1, \times 9$ & $1, \vee v$ & ז צ & $r, \ldots$ & دور الزوجة في الأسرة \\
\hline$* * *, \cdots$ & $10 \leq, 7$ & 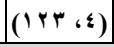 & $r, I V$ & - & $1, \ldots$ & $1, \leqslant 0$ & $1, \wedge r$ & r,0 & $r, \ldots$ & عمل الزوجة وأثرة في استقرار الأسرة \\
\hline
\end{tabular}

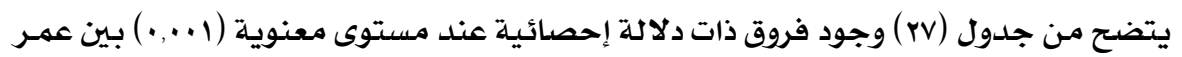

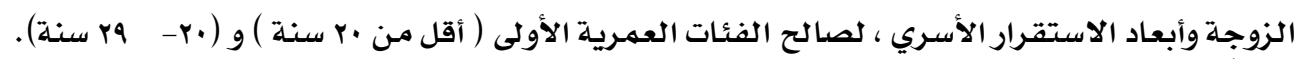

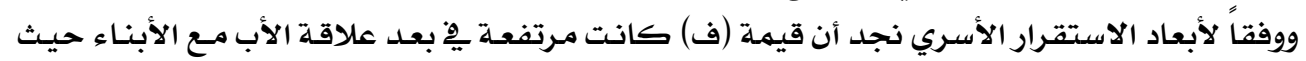

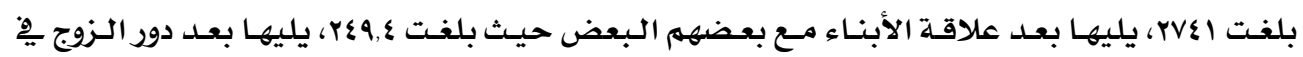

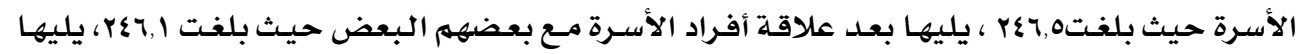

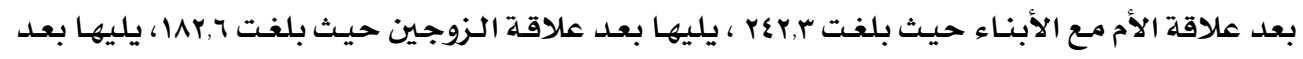

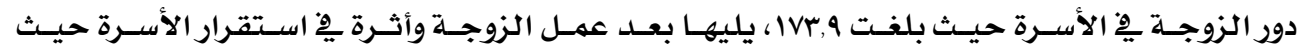

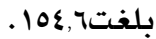




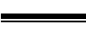

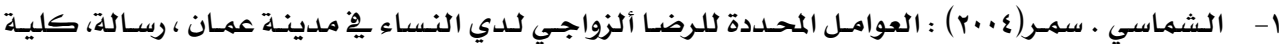
الدراسـات العليا ، جامعة الأردن.

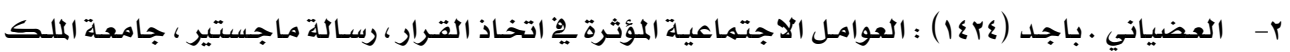
سعود ، الرياض

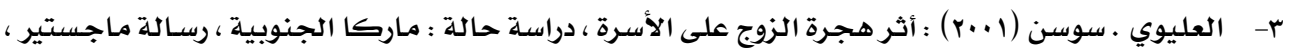

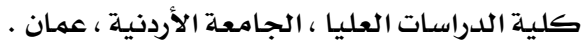
ع- القبلان • يوسف (1991) : مفاهيم يِّ السلوك الإداري ، عالم الكتب ، القاهرة

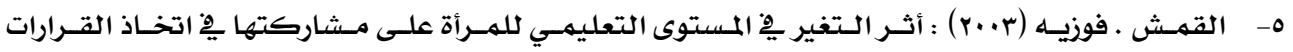

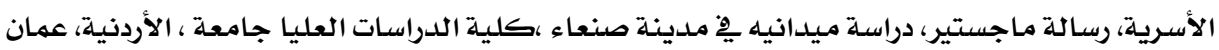
צ- توفيق • سميحة (1997) : مدخل إلي العلاقات الأسرية ، دار المعرفة الجـامعية ، القاهرة .

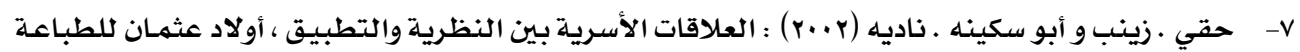
والنشر، القاهرة .

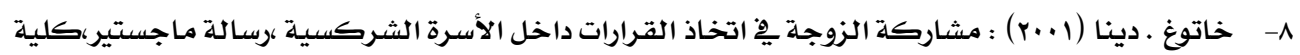

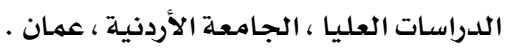

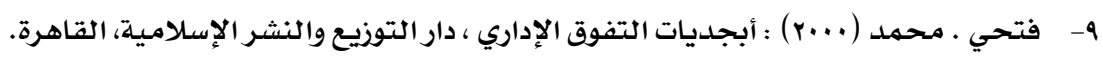

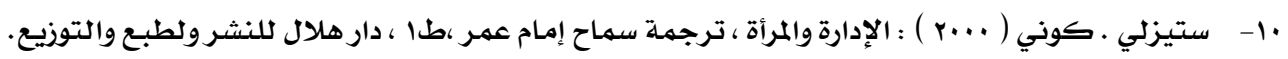
11- Raymond M. Clead J.R.,(1990): Management Information System. Forth Ed. Macmillan. Pub. Company New York. P.108. 